OPEN ACCESS

Edited by:

Antonio Di Bartolomeo,

University of Salerno, Italy

Reviewed by:

Jinquan Wei,

Tsinghua University, China Qingyu Peng,

Harbin Institute of Technology, China

*Correspondence:

Federico Cesano

federico.cesano@unito.it

Specialty section:

This article was submitted to Carbon-Based Materials,

a section of the journal

Frontiers in Materials

Received: 09 March 2020

Accepted: 15 June 2020

Published: 03 September 2020

Citation:

Cesano F, Uddin MJ, Lozano K Zanetti M and Scarano D (2020) All-Carbon Conductors for Electronic and Electrical Wiring Applications.

Front. Mater. 7:219.

doi: 10.3389/fmats.2020.00219

\section{All-Carbon Conductors for Electronic and Electrical Wiring Applications}

\author{
Federico Cesano ${ }^{1 *}$, Mohammed Jasim Uddin², Karen Lozano ${ }^{3}$, Marco Zanetti' and \\ Domenica Scarano' \\ ${ }^{1}$ Department of Chemistry, NIS (Nanostructured Interfaces and Surfaces) Interdepartmental Centre and INSTM Centro di \\ Riferimento, University of Turin, Turin, Italy, ${ }^{2}$ Photonics and Energy Research Laboratory, Department of Chemistry, \\ The University of Texas Rio Grande Valley, Edinburg, TX, United States, ${ }^{3}$ Center for Nanotechnology, Department \\ of Mechanical Engineering, The University of Texas Rio Grande Valley, Edinburg, TX, United States
}

Electrical conductors based on carbons have recently attracted a growing interest due to the prospect of replacing metals. Electrical conductors without metals could represent not only an alternative for traditional wiring, but also a step forward in the progress and advancing of technology. This result can be achieved by combining high electrical conductivity with other properties, that are dexterity, light weight, environmental stability, high strength and flexibility. As the best mechanical properties, high electrical/thermal conductivity of the assembled fibers are all generally associated with low concentration of defects in the fiber backbone and in the individual carbon "building blocks", a special attention is paid to an empirical relationship between morphology/structure/composition and the electrical properties. In this review, starting from the beginning, from the late 19th century, when the carbon filaments became the lights for urban streets, some of the recent developments in the field of "all-carbon" electrical conductors are discussed. Such conductors can be obtained by assembling nanoscale carbons (i.e., carbon nanotubes, graphene) into macroscopic fibers, yarns and ropes (hereafter fibers). In this perspective, the role played by the chemistry in particular by means of the molecularlevel control and doping, is emphasized. This contribution elucidates most recent results in the field, and envisages new potential applications.

Keywords: graphene, carbon nanotubes, carbon fibers, graphene fibers, CNT fibers, yarns, doped carbon, electrical conductivity

\section{INTRODUCTION}

Due to the growing interests about new electrically conductive materials with superior characteristics than the conventional conductors, a detailed knowledge of the electrical properties of carbon-based materials is mandatory. Obviously, the electrical properties are not the only element of evaluation for a possible use of alternative electrical conductors. Other characteristics, including thermal and mechanical properties, chemical and thermal resistance, low weight and density, the heat removal efficiency, and interconnections with traditional wires, reliability and durability, should also be considered.

Many carbon nanomaterials are currently prepared and used as such or are embedded in multiphase materials involving polymers (Haznedar et al., 2013; Cesano and Scarano, 2015; Cesano et al., 2016). However, highly conductive carbon conductors are available in form of assemblies, which contain nanocarbons with a small length/size compared to metal conductors 
(Fang et al., 2020). The lack of progress in the fabrication of "single domain" continuous carbon nanotube and graphene fibers has offered the motivation for building carbon-based macroscopic assemblies with improved electrical, mechanical, thermal and electrochemical properties (Zhang et al., 2007; Lu et al., 2012, 2017, 2019; Miao, 2013; Mäder et al., 2015; Kou et al., 2017; Dhanabalan et al., 2019; Foroughi and Spinks, 2019; Yang et al., 2020; Yin et al., 2020). In analogy with conventional metal wires, carbon nanotubes and graphene-based conductors have reached electrical properties of their metal counterparts, they possess numerous advantages, such as lower weight, high mechanical properties, sensing properties, resistance to extreme conditions, thermal and electrical conductivities (Cesano et al., 2013; Cravanzola et al., 2013; Cesano and Scarano, 2018; Chowdhury et al., 2019; Harun et al., 2019). On the other hand, metals are present in nature with limited amounts and the need for an advantageous alternative solution would be of great relevance. Under these perspectives, it is important to remark that many reviews concerning the main topic of the carbon-based materials and properties are present and that a certain number of them (Chou et al., 2010; Lu et al., 2012; Cong et al., 2014; Lekawa-Raus et al., 2014b; Li and Pandey, 2015; Li et al., 2015; Xu and Gao, 2015; Kou et al., 2017; Yadav et al., 2017; Xu et al., 2019; Zhang et al., 2019; Zheng et al., 2020) should be nevertheless deemed of a great significance. Along with recent findings, Zheng et al. (2020) have recently demonstrated the ultrafast electro-thermal response $\left(5943 \mathrm{~K} \mathrm{~s}^{-1}\right)$ of graphene fibers surpassing the record value of carbon nanotubes. The authors have shown the structural engineering of the graphene fiber assembly, where entanglements of individual graphene nanosheets is beneficial to achieve very low density (0.015$0.020 \mathrm{~g} / \mathrm{cm}^{-3}$ ), together with high mechanical strength (c.a. 3.9 MPa), high specific electrical conductivity (SEC) (0.95-1.67 S $\mathrm{m}^{2} / \mathrm{g}$ ) and specific thermal conductivity (STC) $(42.3-100 \mathrm{~W}$ $\mathrm{cm}^{2} \mathrm{~K}^{-1} \mathrm{~g}^{-1}$ ) values, which are comparable to those of metals $\left(\mathrm{SEC}_{\mathrm{Cu}}\right.$ : $6.61 \mathrm{~S} \mathrm{~m}^{2} \mathrm{~g}^{-1}$; STC $\mathrm{Cu}$ : $0.45 \mathrm{~W} \mathrm{~cm} \mathrm{~K}^{-1} \mathrm{~g}^{-1}$; $\mathrm{SEC}_{\mathrm{Ag}}$ : $5.98 \mathrm{~S} \mathrm{~m}^{2} \mathrm{~g}^{-1}$; STC $\mathrm{Ag}$ : $0.40 \mathrm{~W} \mathrm{~cm}^{2} \mathrm{~K}^{-1} \mathrm{~g}^{-1}$ ). Hills et al. (2019) have recently demonstrated that microprocessors (called 16bit RV16X-NANO microprocessor handling 32-bit instructions of the RISC-V architecture) made of carbon nanotube FETs on $\mathrm{Si}$ wafers can be fabricated. Together with the validation of the microprocessor under working conditions, including instruction fetching, decoding, registering, execution units, and back writing to memory, the authors proposed a manufacturing methodology for manipulation, doping, etching and assembling of carbon nanotubes, for overcoming nanoscale imperfections at macroscopic scales and figuring out industrial standards. At the same time, Afroj et al. (2019) reported the engineering of graphene oxide and graphene flakes by means of the highspeed fiber dyeing technique to coat conventional textiles. The process has the potential to produce tons of conductive graphenebased yarn using existing textile machineries. The authors also shown that the derived textile maintains its conductivity after some washing cycles. Furthermore, a number of recent studies has demonstrated various functions of graphene and carbon nanotube-based yarns, including sensors and biosensors, actuators, energy harvesting and storage devices, catalysis
(Foroughi and Spinks, 2019; Jang et al., 2019; Panwar et al., 2019; Wang et al., 2019; Fang et al., 2020). These recent examples, together with the critical investigation of the literature indicate that the scientific background on this subject is, however, plentiful and rapidly rising, but extremely various and it is nearly unattainable to afford a complete description of all the possible applications. For this reason, the purpose of the present review is to provide a selection of insights dedicated to electrical properties of micro-assembled nanocarbon fibers with no metal present (hereafter all-carbon fibers).

\section{THE FIRST DEVELOPED CARBON CONDUCTIVE WIRES}

In 1838, Marcellin Jobard was the first who experienced a "glow lamp" based on carbon, a vacuum bulb containing a small strip of carbon used as a conductor of a current, emitting an intense, fixed, and durable light. In the late century, Henry Woodward, Mathew Evans, Joseph W. Swan, Thomas A. Edison and Alessandro Cruto were among the first scientists pioneering on electric lighting. After the first approaches with metal filaments placed outside or inside a vacuum bulb, apart from one another they realized that low cost, high-resistance filaments of about a few hundred ohms were required for reducing the sizes of the electric lamps. Thus, pyrolyzed carbon filaments were identified as the best possible candidate materials and some of whom filed separately patents. Edison and Swan are perhaps the more famous, but not the first inventors of the electric lamp, while the most durable ones were probably obtained by Alessandro Cruto. In this context, besides the higher number of patents, Edison's contribution has been a series of requirements, characteristics and methods required to fabricate durable electrical lamps. After about 20 years, in 1904, a new revolution appeared in the light bulbs: the tungsten coiled coils in a bulb filled with inert gas soon substituted carbon filaments, due to its brighter light and better durability.

\section{CARBON FIBERS}

The fabrication of carbon fibers could be traced back to Joseph Swan, who in 1860 produced for the first time carbon fibers from cellulose filaments for light bulb applications, but the first highperformance carbon fibers were manufactured only one century later (1958) by Union Carbide. Such fibers were fabricated by heating under inert gas at a relatively high temperature rayon fibers until their carbonization. However, the method was demonstrated to be ineffective, because fibers were stiff, with low strength and contained only c.a. $20 \%$ of carbon. In the early 1960s, new processes from polyacrylonitrile (PAN) were developed to produce carbon fibers made of more than 99\% carbon and in the next years new generation carbon fibers with high-tensile modulus and mechanical strength were obtained by playing with process parameters (very high temperature) and precursor types (i.e., rayon, PAN, pitch). The carbonization at high temperature was optimized to eliminate heteroatoms $(\mathrm{N}$, 


\section{A

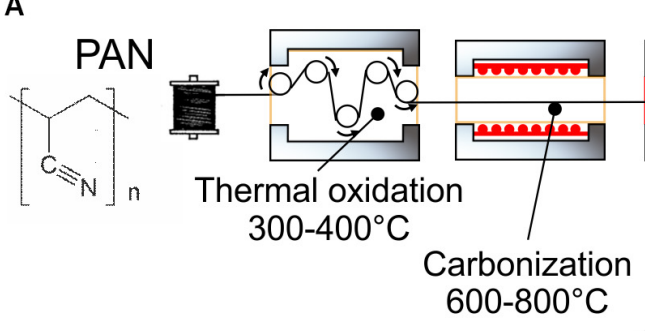

B

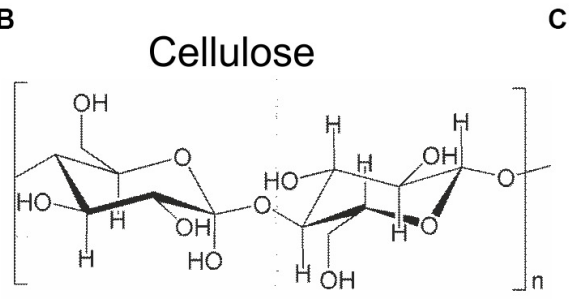

C

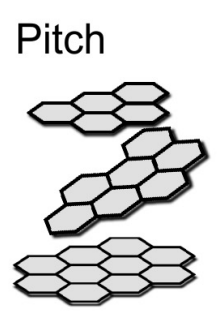

$D$

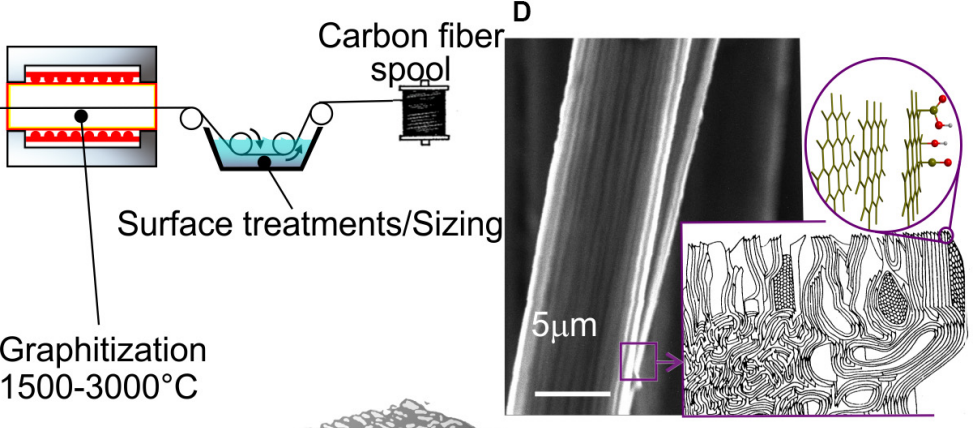

E

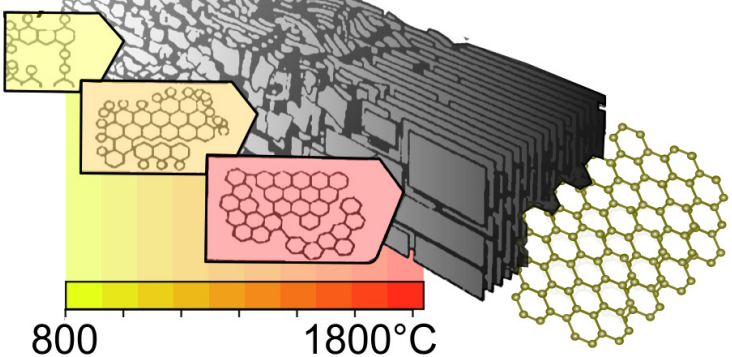

FIGURE 1 | Fabrication steps of carbon fibers from (A) polyacrylonitrile (the most used precursor): oxidation and crosslinking of the PAN fibers, pyrolysis and possibly, the graphitization step occurring at the higher temperatures under inert atmosphere or vacuum conditions; two other conventional precursors of carbon fibers: (B) cellulose and (C) pitch; (D) morphology, structure and surface chemistry of PAN-derived carbon fibers; and (E) evolution of the carbon structure with the increasing temperature from amorphous to crystalline structure (i.e., hexagonal graphite).

$\mathrm{S}, \mathrm{O}, \mathrm{H}$ ) and to constitute a graphitic structure. PAN is by far the most used precursor of today's carbon fibers by following several steps (thermal oxidation, carbonization, graphitization and surface treatments) (Figure 1A), while the other precursors, the cellulose type (including Rayon) and pitch (Figures 1B,C), require different process routes. The morphology of a carbon fiber obtained from PAN is SEM imaged in Figure 1D, together with a few models of the crystalline domain arrangements and surface chemistry. Furthermore, depending on the precursor type and process, carbon fibers can be produced with a wide range of properties: when they are subjected to thermal treatments above $1500-2000^{\circ} \mathrm{C}$, they exhibit a more ordered arrangements (Figure 1E), possess a very high elastic modulus, higher thermal and electrical conductivities and have a carbon content $>99 \%$. Sometimes they are called graphitic fibers. Fibers obtained at lower temperature contain a lower C amount (93-95\%) and possess lower mechanical properties and conductivities. Apart from the foremost use in fiber-reinforced composites, carbon fibers are used in electrode/microelectrodes (i.e., a single carbon fiber), flexible heating applications, whenever a low wear friction on the contact interface is required (e.g., brush contact).

Despite their excellent mechanical properties and some peculiarities (PAN-based fibers have a turbostratic structure: contain basal planes slipped out of their alignment, thus exhibiting high tensile strength, while pitch-derived fibers show higher Young's modulus, high stiffness) and peculiar thermal/electrical conductivities (Chung, 2017), carbon fibers do not represent the end, but the beginning of new classes of fibers. In fact, carbon fibers display a polycrystalline nature
(Figures 1D,E), plenty of grain boundaries/defects, close voids and a rough morphology as schematized in the insets of Figure 1D, with consequent limitation in properties when compared to the graphite counterpart. This can be considered a straightforward consequence of the direct pyrolysis of organic precursors.

\section{VAPOR GROWN CARBON NANOFIBERS (VGCFS), MULTI-WALLED- AND SINGLE-WALLED CARBON NANOTUBES (MWCNTS AND SWCNTS)}

Since the 1950s, the formation of graphitic filaments from hydrocarbons or $\mathrm{CO}$ was observed as deposits, often accidentally, on various substrates inside the tube of furnaces (350$2500^{\circ} \mathrm{C}$ ) (Bacon, 1959). However, the fabrication of carbon fibers and nanofibers became more attractive with the catalytic decomposition of hydrocarbons promoted by metal (i.e., Fe, $\mathrm{Ni}, \mathrm{Co}$, alloys) and metal oxide nanoparticles, due to the lower deposition temperature $\left(350-800^{\circ} \mathrm{C}\right)$ (Tibbetts, 1985). There are many scientific articles, book chapters and books dedicated to this topic. For an in-depth examination of this subject the reader can refer to the specific literature (Iijima and Ichihashi, 1993; Rodriguez et al., 1995; Ajayan, 1999). Briefly, it is important to recall the fact that three different types of precursors (solid, liquid and gas) are of interest. Solid and liquid carbon precursors are attracting the interest owing to their high availability and 


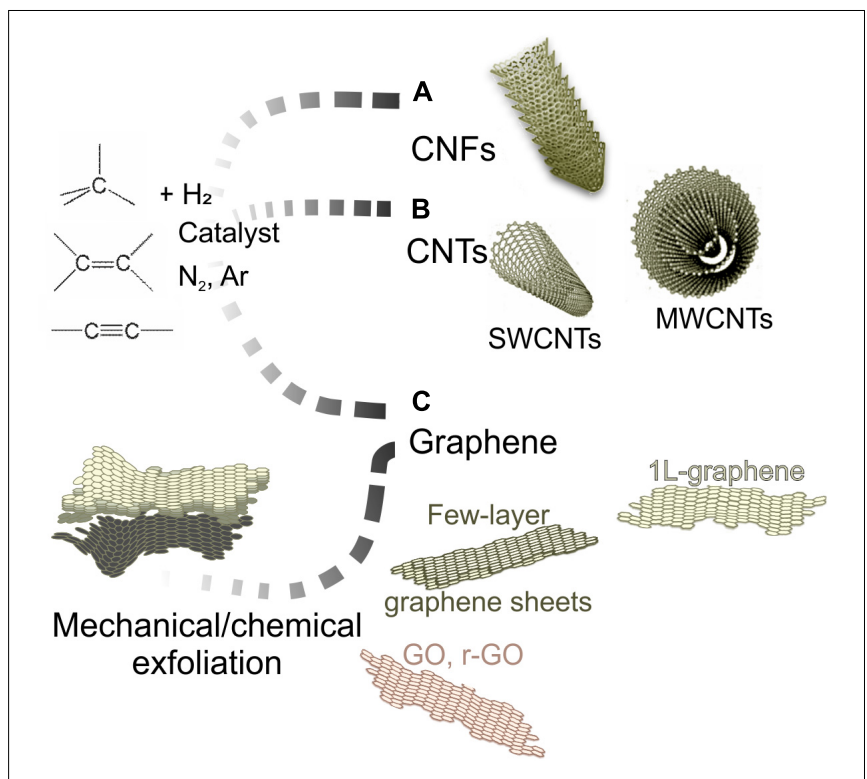

FIGURE 2 | Fabrication scheme of 1D and 2D carbons from molecular precursors (or pre-constituted CNT/graphene structures): (A) carbon nanofibers (CNFs), (B) single-walled and multi-walled carbon nanotubes (SWCNTs, MWCNTs); and (C) 2D carbons obtained from "bottom-up" and "top-down" approaches: graphene, graphene oxide (GO) and reduced graphene oxide ( $\mathrm{r}-\mathrm{GO})$.

low cost, while hydrocarbons are the most popular ones due to the fact that, thanks to their purity, they can be considered as model systems. On this subject, it is commonly accepted that when hydrocarbons are used, the reactions proceed at the exposed surfaces of metal catalyst and carbon nanostructures under formation are shaped by metal nanoparticles (Cesano et al., 2005; Li and Pandey, 2015). The growth mechanism of carbon nanostructures is therefore governed by bulk diffusion, carbon concentration gradients and temperature of reaction (Derbyshire et al., 1975; Iijima et al., 1992; Rodriguez et al., 1995; De Jong and Geus, 2000; Kharlamova, 2017). Depending on the catalyst type, temperature of reaction, metal particle sizes and growth methods, different types of structure can be observed ( $\mathrm{Li}$ and Pandey, 2015; Kharlamova, 2017) (Figures 2A,B). In this regard, carbon nanotubes (SWCNTs and MWCNTs) can be distinguished from nanofibers by the different stacking of the carbon layers, and the little metal nanoparticles are cut out for the synthesis of SWCNTs, whilst bigger catalyst particles promote the MWCNT/nanofiber formation (De Jong and Geus, 2000). In the same way, largearea graphene films can be obtained by following a bottomup approach by using a carbon feedstock and a metal catalyst (i.e., mainly $\mathrm{Cu}, \mathrm{Pt}$, Co, but also $\mathrm{Ni}$ and other metals) and by controlling the hydrocarbon concentration and the cooling rate during graphene growth. The reader may refer to the dedicated literature (Li et al., 2009; Reina et al., 2009). In this manner, the uniformity and the thickness of one- and two- or a few layers can be largely controlled (Lee et al., 2017) (Figure 2C). Deposition at a temperature as low as $300^{\circ} \mathrm{C}$ has been reported by Vishwakarma et al. (2019) by using a microwave plasma CVD method by adopting ppm $\mathrm{CO}_{2}$ during growth from $\mathrm{CH}_{4}$ for the control over vertical graphene growth, and $\mathrm{O}_{3}$ treatment for increasing transmittance and carrier mobility. On the other hands, 2D graphene family materials (i.e., single-layer or fewlayer graphene sheets, graphene oxide and reduced-graphene oxide) with lower quality and smaller lateral sheet dimensions can be obtained by using a top-down approach by following a mechanical or a chemical exfoliation (Harun et al., 2019).

\section{FIBER INTERCONNECTS: VAN DER WAALS INTERACTIONS AND COVALENT BONDING}

It is known that mechanical properties, thermal and electrical conductivities of carbon fibers are limited by presence of defects and by the weak interactions among adjacent fibers (LekawaRaus et al., 2014b; Fang et al., 2020; Wang et al., 2020). Cesano et al. (2005), Veedu et al. (2006), and Anthony et al. (2018) have shown the interconnection of fibers by means of catalytically grown nanofilaments (carbon nanofibers and carbon nanotubes) by using $\mathrm{C}_{2} \mathrm{H}_{4}$ or xylene at 700 and $800^{\circ} \mathrm{C}$ (Figure 3 ).

The authors displayed that the metal nanoparticles (Fe, Ni) go away from the surface of the fibers where they were initially located and move on the tip of the filaments under formation, acting as independent catalytic centers (Cesano et al., 2005). Such catalytic nanoparticles transferred into the structure of the growing nanofilaments, play a big part in the ongoing formation of interconnected CNF entanglement, which connects the adjacent CFs and at later stages the densification of a more compact CNT/CFs composite can be obtained (Figures 3A-D). Recently, Zheng et al. (2020) have shown the 3D assembling of graphene sheets directly grown on carbon fibers by thermal CVD. The carbon nanofibers, previously obtained by electrospinning of PAN fibers, were stabilized (in air) and carbonized at $1100^{\circ} \mathrm{C}$ (under $\mathrm{NH}_{3}$ ). The authors observed a remarkable densification of the graphene nanosheets, with the growth time and the filling of the space between composite fibers for prolonged reactions (10h) (Figures 3E-H). In a recent paper, Karakassides et al. (2020) have recently reported the catalyst-free growth of radially aligned graphene nanoflakes on carbon fibers by means of microwave plasma-enhanced chemical vapor deposition (PECVD) process with $\mathrm{CH}_{4}$ and $\mathrm{N}_{2}$ gas mixture under vacuum conditions (total pressure $=15$ Torr). Together with a remarkable increment of the mechanical properties, the authors observed that both, electrical conductivity and specific capacitance $\left(\mathrm{C}_{\mathrm{sp}}\right)$, resulted to be improved (from c.a. $160 \mathrm{~S} / \mathrm{cm}$ to c.a. $257 \mathrm{~S} / \mathrm{cm}$ and from c.a. $0.27 \mathrm{mF} / \mathrm{cm}^{2}$ to c.a. $0.65 \mathrm{mF} / \mathrm{cm}^{2}$, respectively), due to the reduction of the contact resistance between graphene flakes and carbon fibers.

\section{THE ASSEMBLING OF CNTS AND GRAPHENE TO FORM FIBERS}

CNTs and graphene are well known to be used in polymer matrix composite materials (i.e., bulk materials or films), while 


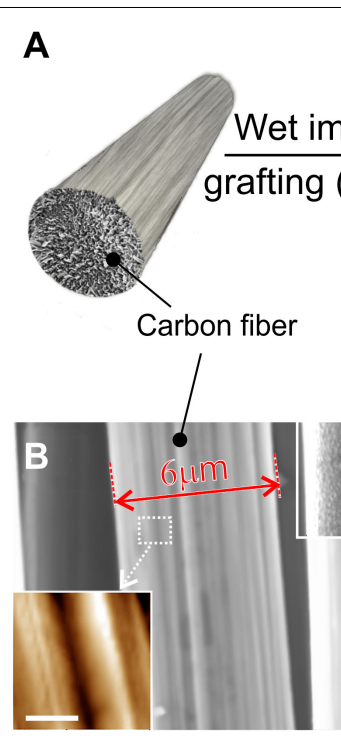

E

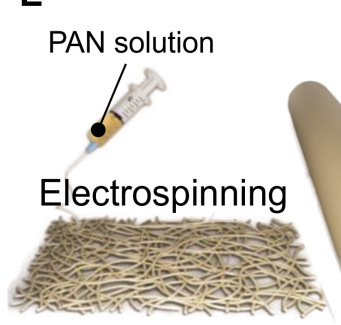

CNTs/CF 3D assembly

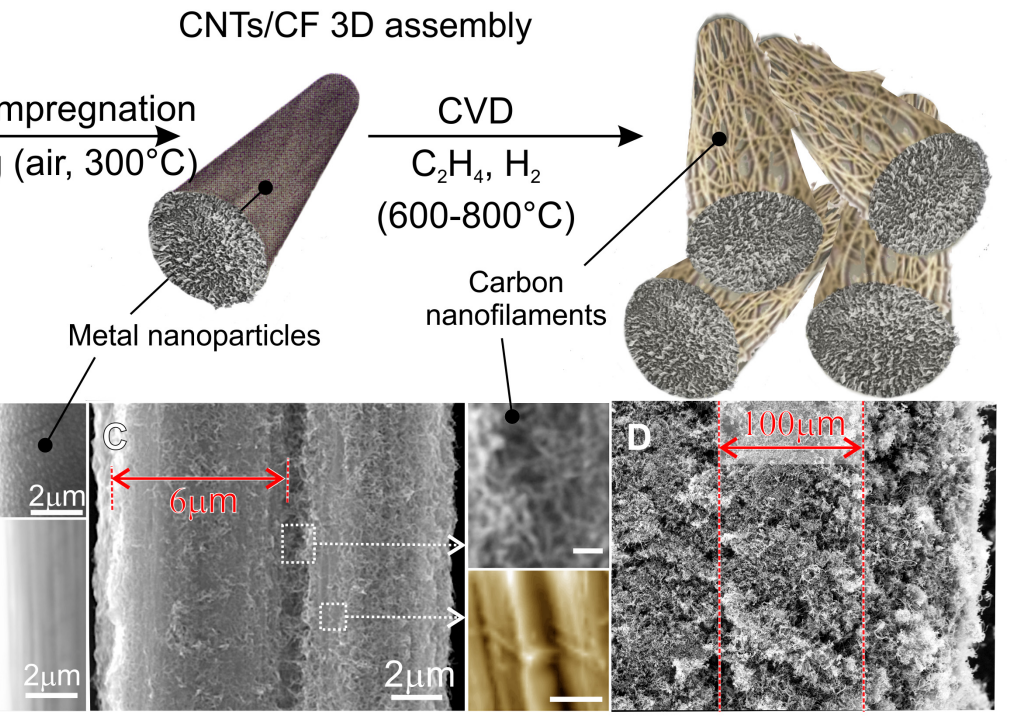

Graphene/CF 3D assembly
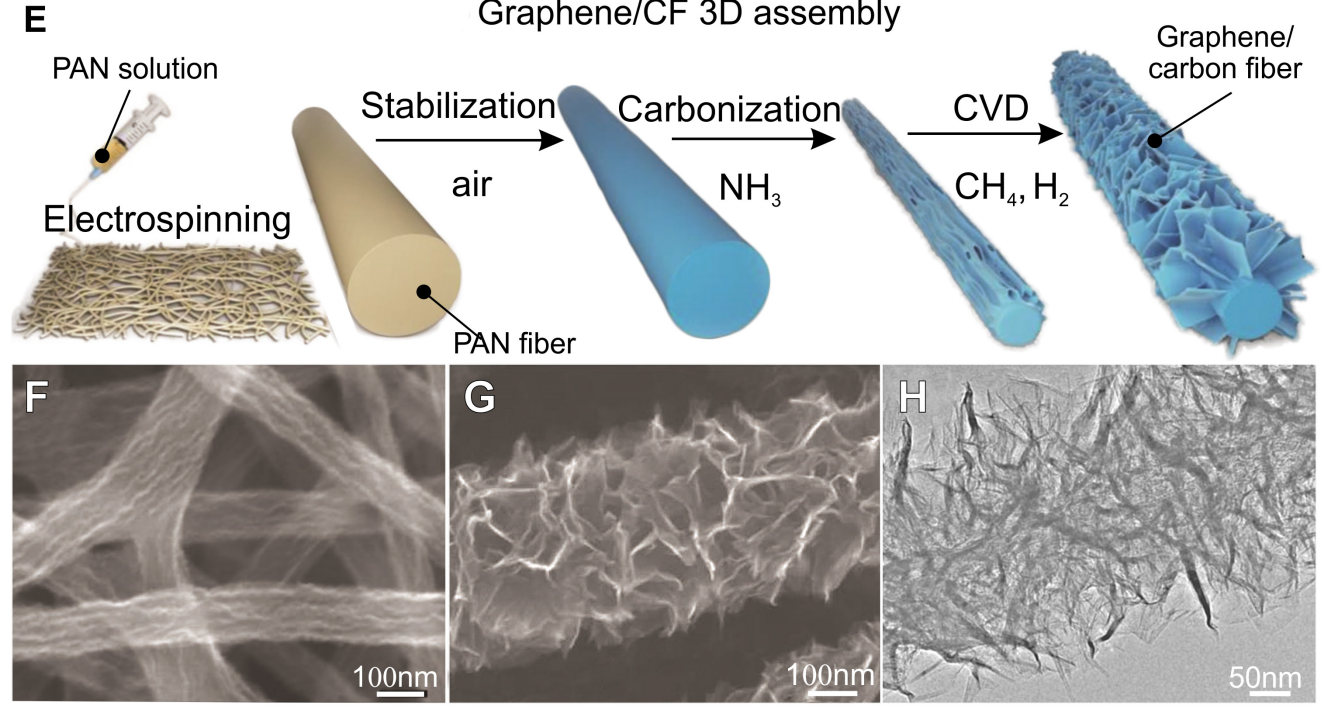

FIGURE 3 | (A) Schematic representation of carbon nanofilaments-interconnected carbon fiber assemblies as obtained by $\mathrm{C}_{2} \mathrm{H}_{4}$ catalytic decomposition at $700^{\circ} \mathrm{C}$; SEM and AFM images of: (B) the native carbon fibers used as support; In the top and bottom insets of (B) the morphologies of a nickel catalyst nanoparticles supported on carbon fiber and of the wrinkled surface of the native carbon fibres; (C) interconnection and (D) densification of the carbon fiber support by carbon nanofilaments as obtained under static (700 Torr) and dynamic conditions (100 ml/min) after 1h of reaction time; (E) schematic representation of carbon fiber-graphene assemblies as obtained by $\mathrm{CH}_{4}$ thermal decomposition at $700^{\circ} \mathrm{C}$; (F) SEM images of the native PAN nanofibers; and (G,H) SEM and TEM images of the graphene-coated carbon fibers. AFM image scalebars are $300 \mathrm{~nm}$. Panels (B-D) adapted from Cesano et al. (2005) with permission from American Chemistry Society. Panels (E-H) adapted from Zeng et al. (2018) with permission from Wiley-VCH.

in some application fields carbon-based polymer fibers find a specific use. In recent papers, Salavagione et al. (2018) and $\mathrm{Lu}$ et al. (2019), reviewed potentialities (and limitations) of CNT/polymer and graphene/polymer fibers, respectively. Briefly, the state of the art of polymer-based fiber shows the potential in some fields of application, including the electromagnetic shielding, wearable and smart textiles or as electrodes, but such composite fibers do not nearly reach the thermal and electrical conductivities of metals. The need to go beyond the characteristics of polymer matrix composites has stimulated the development of nanocarbons assembled into fibers, whose interest is particularly significant from the practical point of view, if they go beyond the mechanical properties of carbon fibers and provide thermal and electrical conductivities close to or beyond those of metals (i.e., $\mathrm{Cu}, \mathrm{Ag}$ ). Although the theme of the carbon-based yarn fabrication is much broader than that described here, it can be further examined in some recent dedicated papers (Miao, 2013; Kou et al., 2017; Zhang et al., 2019; Yin et al., 2020). The quality of CNT and graphene fibers depends on a large extent on the fabrication process, by following solid-state or liquid spinning approaches. The spinning techniques take advantage at the molecular level of 
A
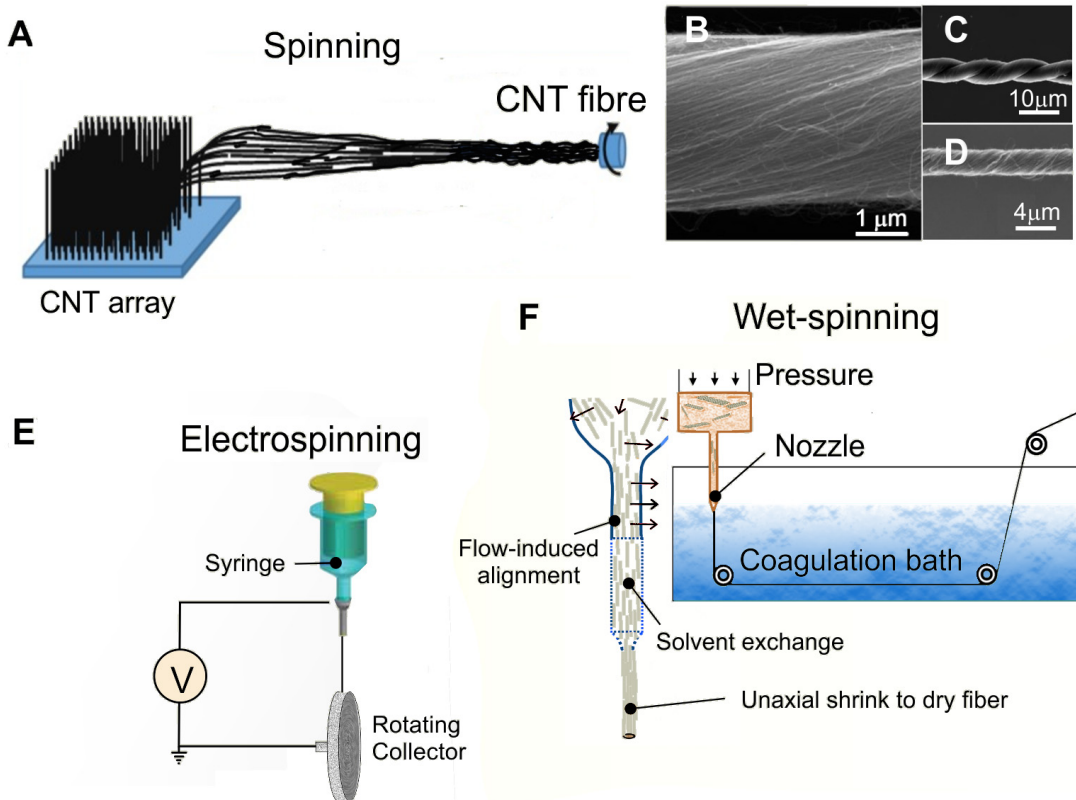

$\mathbf{F}$

Wet-spinning

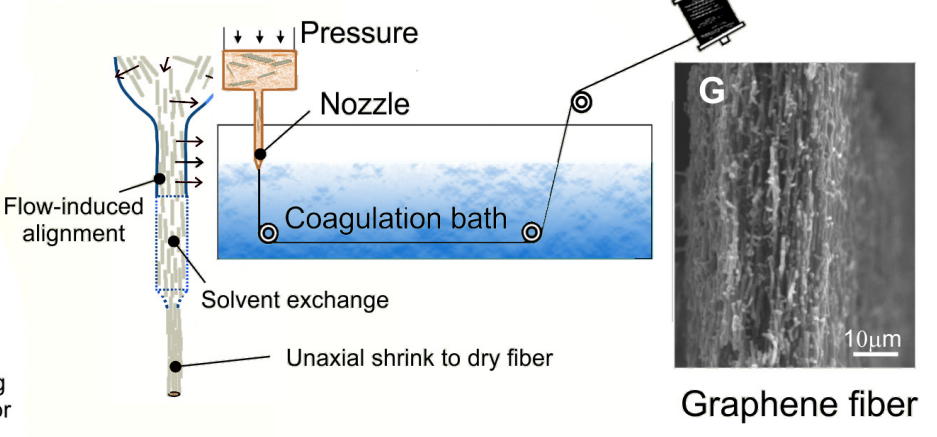

FIGURE 4 | Macroscopic assembling methods of: (A) CNT fibers from a forest of CNT arrays by spinning; (B-D) SEM images of the CNT ropes after spinning and twisting steps; (E) CNT/graphene fibers by electrospinning and (F) graphene fibers by wet-spinning/coagulation methods; and (G) SEM image of the graphene fiber. Panels (B-D) adapted from Zhang et al. (2007) with permission from Wiley-VCH. Panel (G) reproduced from Zeng et al. (2018) with permission from Wiley-VCH.

the polymer science (Cheng and Lee, 2016; Cecone et al., 2018; García-Mateos et al., 2019; Mohammadzadehmoghadam and Dong, 2019).

CNT yarns can be easily obtained from vertically grown CNTs by the direct dry-spinning procedure (Figure 4A) or twisting during spinning taking advantage of the van der Waals forces acting among the vertically grown SWCNTs and/or MWCNTs to arrange them into micro-sized ropes of an unlimited length (Jiang et al., 2002; Li et al., 2004; Zhang et al., 2004, 2005). The resulting structure could be very different depending on the spinning parameters and twisting procedure (if adopted) (Figures 4BD). Otherwise, the CNT and graphene fiber can be obtained by electrospinning or wet spinning procedures (Figures $4 \mathrm{E}, \mathrm{F}$ ), which confer a peculiar morphology to the fiber (Figure 4G). Post treatments have been found to increase the density and the properties of the fibers.

A note can be drawn about the comparison between the different preparation methods for CNT fibers. The yarns can be fabricated by the fixed-catalyst CVD, with CNTs directly spun from a floating-catalyst CVD reactor, which is a relatively more simple and clean procedure (i.e., no solvents and acids are needed) or wet-spinning method. The last procedure can provide fibers with the best conductivity $\left(8.5 \times 10^{4} \mathrm{~S} / \mathrm{cm}\right)$ (Tsentalovich et al., 2017) for CNT fiber probably arising from a doping step, due to the strong acid treatment in the coagulation bath. Below electrical properties of fibers coming from the wet spinning method, the floating-catalyst CVD procedure provides better conductivity, as compared to CNT arrays (Dini et al., 2019). Furthermore, SWCNTs or DWCNTs are by far the best candidates to achieve better fiber performances. The arrangement of nanotubes into aligned CNT arrays yields fibers with much better properties, whilst more entangled arrays give poor characteristics (Kou et al., 2017). Furthermore, the long length and the large aspect ratio of individual nanotubes are known to play a relevant role in achieving good properties. Interestingly, Behabtu et al. (2013) fabricated CNT yarns after dissolving CNTs in chlorosulfonic acid by the wet spinning method, similar to the process commonly used to produce highperformance industrial fibers. Together with electrical properties that will be discussed later, such fibers were tested for mechanical and thermal properties. Briefly, tensile strength (1 GPa) and modulus (120 GPa), were determined together with an elongation at break of $1.4 \%$. The same fibers displayed a thermal conductivity of c.a. $380 \mathrm{~W} / \mathrm{m} \mathrm{K}^{-1}$. The same authors determined the effect of doping with iodine. As a result, the thermal conductivity was increased by $100 \%\left(635 \mathrm{~W} / \mathrm{m} \mathrm{K}^{-1}\right)$ even after thermal annealing at $600^{\circ} \mathrm{C}$. From these, we can conclude that optimal morphology and structure (i.e., alignment of CNTs, high packing density, lack of impurities and defects) are crucial for the final properties of CNT fibers.

As far as graphene fibers are concerned, the two-dimensional structure and crystal domains with finite dimensions dictate a few considerations. First of all, layered structures are very flexible, but their structural organization in a yarn of indefinite length, implies a stacking (Figure 5). A full scale approach to minimize defects from atomic to macroscale levels was attempted by $\mathrm{Xu}$ et al. (2016). The authors used large GO liquid crystals and the wetspinning method with continuous stretching during the process to obtain the ordered orientation of graphene sheets along the axis of fibers. The control over the concentration and nozzle 


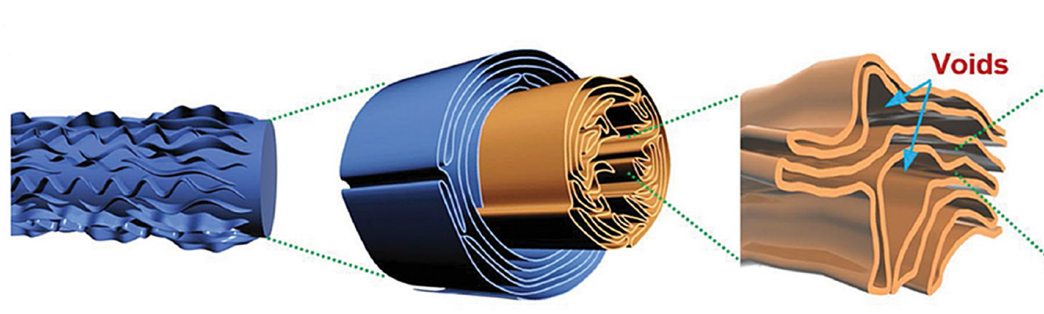

Random wrinkles Core-sheath inhomogeneity Packing faults/voids

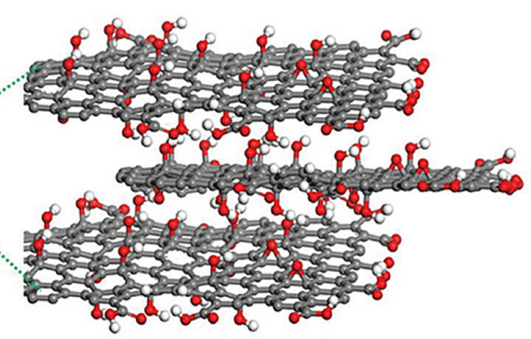

Amorphous defective graphene

Macroscale Microscale Nanoscale Atomic scale

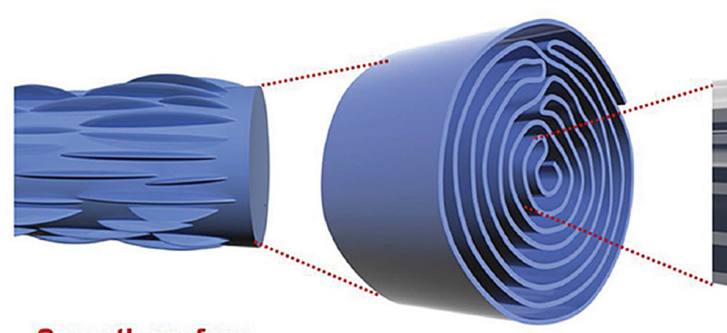

Smooth surface

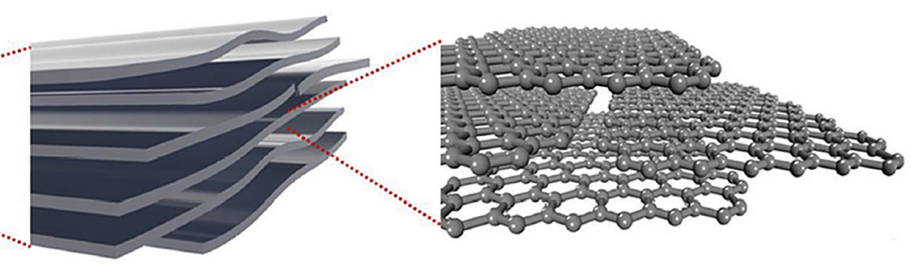

Dense packing
Defect-free graphene

with aligned wrinkles

FIGURE 5 | Structural models of: defects in GFs from the macroscale to the atomic scale of chemically reduced GO (top panels); high-quality defect-free GFs (bottom panels). Adapted from Xu et al. (2016) with permission from Wiley-VCH.

diameter together with the thermal treatment at $3000^{\circ} \mathrm{C}$ helped to perfect the atomic structure of graphene. The obtained fibers demonstrated a series of record properties, including ultrahigh stiffness $(282 \mathrm{GPa})$, tensile strength $(1.45 \mathrm{GPa})$ high electrical conductivity $\left(8 \times 10^{5} \mathrm{~S} \mathrm{~m}^{-1}\right)$ and ampacity $\left(2.3 \times 10^{10} \mathrm{~A} \mathrm{~m}^{-2}\right)$.

\section{HIGHLY ELECTRICALLY CONDUCTIVE METAL-LESS CONDUCTORS}

Conventional and unconventional materials for electrical wiring are listed in Table 1. In almost all cases, the Drude model of electrical conduction is a good approximation. Among metals, the best conductors have one electron in their outermost shell layer (metal Cu: 2, 8, 18, 1; metal Ag: 2, 8, 18, 18, 1; and Au: $2,8,18,32,18,1)$. It is well known that conventional electrical conductors operating nearly room temperature are commonly based on copper $\left(5.8 \times 10^{5} \mathrm{~S} / \mathrm{cm}\right)$ or silver $\left(6.4 \times 10^{5} \mathrm{~S} / \mathrm{cm}\right.$ at $25^{\circ} \mathrm{C}$ ). Both metals require only a weak field to strip one electron as compared to other metals or elements. Graphite is a non-metallic material two orders less conductive than metals $\left(2-3 \times 10^{3} \mathrm{~S} / \mathrm{cm}\right)$. Depending on the precursor type, the preparation process and the heating temperature, carbon fibers exhibit a relatively lower conductivity than graphite. The conductivity at room temperature is, for a fact, found to be unaffected by heating the material up to $\approx 2500^{\circ} \mathrm{C}$, while above this temperature, it increases becoming closer to that of graphite (Tsukamoto et al., 1986).

In principle, an assembled carbon yarn could virtually transport electricity like a ballistic conductor and the behavior could be well interpreted in terms of electrons and holes with the Drude model of electrical conduction (Fujita and Suzuki, 2010). However, fibers made exclusively of the same metallic (armchair) SWCNT type or graphene strips, defect-free and infinitely long, are by now technologically unfeasible. Thess et al. (1996) observed the self-organization of SWCNTs into ropes of 5-20 $\mathrm{nm}$ in diameter. The authors measured at room temperature a resistivity of c.a. $10^{-4} \Omega \mathrm{cm}$ (c.a. $10^{4} \mathrm{~S} / \mathrm{cm}$ ), a value that is two orders of magnitude higher than that of single metallic CNTs. The conductivity of individual tubes is often two orders of magnitude larger than their assemblies, thus highlighting the role played by the contact resistances at the interfaces of the single nanotubes (Li et al., 2007). As the overlap of nanoconductors make possible electrical connections and that an infinite number of junctions is present in the fiber, $\mathrm{Xu} \mathrm{F}$. et al. (2013) demonstrated that the energy gap introduced by long junctions can be overcome by small voltage $(\sim 0.04 \mathrm{~V})$ across the whole fiber. Lekawa-Raus et al. (2017) calculated that there is a theoretical conductance limit, which depends on the fiber length, and is $5.9 \times 10^{11} \mathrm{~S} / \mathrm{m}, 5.9 \times 10^{13} \mathrm{~S} / \mathrm{m}$ or $5.9 \times 10^{16} \mathrm{~S} / \mathrm{m}$ for a $1 \mathrm{~cm}, 1 \mathrm{~m}$ or $1 \mathrm{~km}$ long fiber of $10 \mu \mathrm{m}$ in diameter, constituted by (metallic) $(10,10)$ armchair SWCNTs. Interestingly, the authors have also demonstrated that the conductivity scales inversely proportionally to the CNT diameter for an ideal fiber. Barnett et al. (2019) and Lepak-Kuc et al. (2019) have shown via experimental and theoretical approaches the dependence of the electrical contact resistance at the junction regions between CNTs (SWCNTs and/or MWCNTs) and between CNTs and graphene interfaces by considering morphology, structure (i.e., chirality). Interestingly, it was shown that when there is a large 
TABLE 1 | Electrical properties at room temperature of CNT/graphene-based fibers, including some reference materials,

\begin{tabular}{|c|c|c|c|c|c|c|}
\hline Materials/Fibers & $\begin{array}{l}\text { Electr. conductivity, } S / \mathrm{cm} \\
\quad \text { (resistivity, } \Omega \mathrm{cm})\end{array}$ & $\begin{array}{l}\text { Specific conductivity, } \\
\qquad \mathrm{S} \mathrm{m}^{2} \mathrm{~kg}^{-1}\end{array}$ & $\mathrm{~J}_{\max }, \mathrm{A} \mathrm{cm}^{-2}$ & Density, $\mathbf{g} / \mathrm{cm}^{3}$ & $\begin{array}{l}\text { Surface area, } \mathrm{m}^{2} / \mathrm{g} \\
\text { (Porosity, \%) }\end{array}$ & References \\
\hline \multicolumn{7}{|l|}{ Some metals/reference materials: } \\
\hline Copper & $5.85 \times 10^{5}\left(1.7 \times 10^{-6}\right)$ & $6.73 \times 10^{3}$ & $2.17 \times 10^{5}$ & 8.69 & & Ross, 1992 \\
\hline Silver & $6.45 \times 10^{5}\left(1.55 \times 10^{-6}\right)$ & $6.15 \times 10^{3}$ & & 10.49 & & Ross, 1992 \\
\hline Alumium & $3.7 \times 10^{5}\left(2.7 \times 10^{-6}\right)$ & $1.37 \times 10^{4}$ & & 2.7 & & Ross, 1992 \\
\hline Gold & $4.55 \times 10^{5}\left(2.2 \times 10^{-6}\right)$ & $2.36 \times 10^{3}$ & & 19.32 & & Ross, 1992 \\
\hline Graphite $\perp$ c-axis $=c$-axis & $1.02 \times 10^{3}\left(9.8 \times 10^{-4}\right)$ & $4.51 \times 10^{1}$ & & 2.26 & & Powell and Childs, 1972 \\
\hline PAN-based carbon fibers & $\sim 0.1-1 \times 10^{3}\left(\sim 0.1-1 \times 10^{-3}\right)$ & $\sim 0.1-10 \times 10^{1}$ & & $\sim 1.6-2$ & & Newcomb and Chae, 2018 \\
\hline Pitch-based carbon fibers & $\sim 0.1-1 \times 10^{3}\left(\sim 0.1-1 \times 10^{-3}\right)$ & $\sim 0.1-10 \times 10^{1}$ & & $\sim 1.7-2.1$ & & Newcomb and Chae, 2018 \\
\hline SWCNTS & $\sim 1 \times 10^{6}\left(1 \times 10^{-6}\right)$ & $\sim 7.7 \times 10^{4}$ & $\sim 4 \times 10^{9}$ & 1.3 & & Hong and Myung, 2007 \\
\hline Radially grown GR/carbon fiber yarns & $2.6-5.9 \times 10^{2}\left(1.7-3.9 \times 10^{-3}\right)$ & $1-3 \times 10^{1}$ & & 2 & & Karakassides et al., 2020 \\
\hline High T annealed GR film & $1 \times 10^{4}\left(1 \times 10^{-4}\right)$ & & & & & Peng et al., 2017 \\
\hline $\mathrm{MoCl}_{5}$-intercalated GR film & $1.1-1.7 \times 10^{5}\left(5.8-9.1 \times 10^{-6}\right)$ & $4.1-7.3 \times 10^{3}$ & & 2.37 & & Liu Y. et al., 2020 \\
\hline K-doped GR film & $1.2-1.5 \times 10^{5}\left(6.7-8.3 \times 10^{-6}\right)$ & $6.0-9.1 \times 10^{3}$ & & $1.45-1.63$ & & Zhou et al., 2017 \\
\hline \multicolumn{7}{|l|}{ CNT fibers: } \\
\hline Metallic-based SWCNT yarns & - & $2 \times 10^{6}$ & & & & Sundaram et al., 2011 \\
\hline $\begin{array}{l}\text { High aligned SWCNT and MWCNT } \\
\text { fibers }\end{array}$ & $\sim 1 \times 10^{4}\left(\sim 1 \times 10^{-4}\right)$ & 2270 & & & & Lee J. et al., 2019 \\
\hline DWCNT yarns & $5 \times 10^{3}\left(2 \times 10^{-4}\right)$ & $\sim 5 \times 10^{2}$ & & $\sim 1.0$ & & Zhong et al., 2010 \\
\hline $\begin{array}{l}\text { SWCNTs or DWCNTs, wet-spinning } \\
\text { sol. in acid }\end{array}$ & $8.50 \times 10^{4}\left(1,18 \times 10^{-5}\right)$ & $5.7 \times 10^{3}$ & & 1.5 & & Tsentalovich et al., 2017 \\
\hline Thin MWCNTs, wet-spinning sol. & $1.82 \times 10^{4}\left(5.49 \times 10^{-5}\right)$ & $\sim 1.2 \times 10^{3}$ & & $1.3-1.8$ & & Wang et al., 2014 \\
\hline MWCNT yarns & $300\left(3.3 \times 10^{-3}\right)$ & $3.75 \times 10^{1}$ & & & & Mirfakhrai et al., 2008 \\
\hline MWCNT purified yarns & $400-800\left(2.5-1.25 \times 10^{-3}\right)$ & $4.4-8.9 \times 10^{1}$ & & & & Jakubinek et al., 2012 \\
\hline $\begin{array}{l}\text { (2000-MWCNT purified yarns } \\
2500^{\circ} \mathrm{C} \text { ) annealed MWCNT yarns }\end{array}$ & $1.32 \times 10^{3}\left(7.6 \times 10^{-4}\right)$ & & & & & Dini et al., 2020 \\
\hline \multicolumn{7}{|l|}{ Graphene fibers: } \\
\hline $\begin{array}{l}\text { Hyperbranched polyglycerol-based } \\
\text { fibers }\end{array}$ & $2.51 \times 10^{1}\left(3.99 \times 10^{-2}\right)$ & & & & 2210 & Aboutalebi et al., 2014 \\
\hline $\begin{array}{l}\text { GR composite fibers by } \\
\text { electrospinning/CVD/soaking } \\
\text { sequential method }\end{array}$ & $4.59 \times 10^{1}\left(2.18 \times 10^{-2}\right)$ & & & & 9.8 & Sun et al., 2018 \\
\hline 3D assembled GR fibers & $0.34-1.2 \times 10^{3}\left(0.83-2.9 \times 10^{-3}\right)$ & $\sim 1.3 \times 10^{2}$ & & & & Zeng et al., 2018 \\
\hline $\begin{array}{l}\text { Polydopamine/GO fibers annealed } \\
\text { @1200 } \mathrm{C}\end{array}$ & $6.6 \times 10^{2}\left(1.52 \times 10^{-3}\right)$ & & & & & Ma et al., 2018 \\
\hline $\begin{array}{l}\text { Large/small GR sheets annealed } \\
@ 1400^{\circ} \mathrm{C}\end{array}$ & $5.5 \times 10^{2}\left(1.82 \times 10^{-3}\right)$ & $\sim 4.2 \times 10^{1}$ & & 1.3 & $(42 \%)$ & Xin et al., 2019 \\
\hline $\begin{array}{l}\text { Large/small GR sheets annealed } \\
@ 2000^{\circ} \mathrm{C}\end{array}$ & $1.5 \times 10^{3}\left(6.67 \times 10^{-4}\right)$ & $\sim 1.01 \times 10^{2}$ & & 1.48 & $(34 \%)$ & Xin et al., 2019 \\
\hline
\end{tabular}


TABLE 1 | Continued

\begin{tabular}{|c|c|c|c|c|c|c|}
\hline Materials/Fibers & $\begin{array}{l}\text { Electr. conductivity, } S / \mathrm{cm} \\
\quad \text { (resistivity, } \Omega \mathrm{cm})\end{array}$ & $\begin{array}{l}\text { Specific conductivity, } \\
\qquad \mathrm{S} \mathrm{m}^{2} \mathrm{~kg}^{-1}\end{array}$ & $J_{\max }, A$ cm $^{-2}$ & Density, $\mathrm{g} / \mathrm{cm}^{3}$ & $\begin{array}{l}\text { Surface area, } \mathrm{m}^{2} / \mathrm{g} \\
\text { (Porosity, \%) }\end{array}$ & References \\
\hline $\begin{array}{l}\text { Large/small GR sheets annealed } \\
@ 2500^{\circ} \mathrm{C}\end{array}$ & $1.6 \times 10^{3}\left(6.25 \times 10^{-4}\right)$ & $\sim 1.03 \times 10^{2}$ & & 1.55 & $(31.5 \%)$ & Xin et al., 2019 \\
\hline $\begin{array}{l}\text { Large/small GR sheets annealed } \\
@ 2850^{\circ} \mathrm{C}\end{array}$ & $1.79 \times 10^{3}\left(5.59 \times 10^{-4}\right)$ & $\sim 1.13 \times 10^{2}$ & & 1.58 & $(30 \%)$ & Xin et al., 2019 \\
\hline $\begin{array}{l}\text { As before, optimized GR fibers, } \\
\text { annealed } @ 2850^{\circ} \mathrm{C}\end{array}$ & $2.1 \times 10^{3}\left(4.76 \times 10^{-4}\right)$ & $\sim 1.13 \times 10^{2}$ & & 1.86 & $(18.5 \%)$ & Xin et al., 2019 \\
\hline $\begin{array}{l}\text { GR fibers annealed @2500 } \mathrm{C} \text {, } \\
\text { wet-spinned with microfluidic } \\
\text { approach }\end{array}$ & $1.04 \times 10^{4}\left(9.62 \times 10^{-5}\right)$ & $6.5 \times 10^{2}$ & & & & Xin et al., 2019 \\
\hline GR fibers annealed @ $3000^{\circ} \mathrm{C}$ & $8.3 \times 10^{3}\left(1.2 \times 10^{-4}\right)$ & $\sim 2.3 \times 10^{3}$ & $2.3 \times 10^{6}$ & & & Xu et al., 2016 \\
\hline GR fibers & $8,0 \times 10^{3}$ & & & & & Liu et al., 2016 \\
\hline GR fibers $@ 3000^{\circ} \mathrm{C}$ doped with Ca & (superconducting $\leq 11 \mathrm{~K}$ ) & & & & & Liu et al., 2017 \\
\hline \multicolumn{7}{|l|}{ Doped CNT fibers: } \\
\hline $\mathrm{H}_{2} \mathrm{SO}_{4}$-doped SWCNT yarns & $5 \times 10^{3}\left(2 \times 10^{-4}\right)$ & $\sim 5 \times 10^{2}$ & & 1.11 & & Ericson et al., 2004 \\
\hline $\begin{array}{l}\text { N-doped rGO/acid-oxidized SWNT } \\
\text { composite fibers }\end{array}$ & $1.02 \times 10^{3}\left(9.8 \times 10^{-4}\right)$ & & & & 396 & Yu et al., 2014 \\
\hline $\begin{array}{l}\left(2000-2500^{\circ} \mathrm{C}\right) \text { annealed and } \\
\mathrm{PtCl}_{4} \text {-doped MWCNT yarns }\end{array}$ & $1 \times 10^{5}\left(1 \times 10^{-5}\right)$ & & & & & Dini et al., 2020 \\
\hline $\mathrm{HSO}_{3} \mathrm{Cl}$-doped coagulation bath & $7.7 \times 10^{4}\left(1.3 \times 10^{-5}\right)$ & $4.9 \times 10^{3}$ & & 1.58 & & Headrick et al., 2018 \\
\hline $\begin{array}{l}\text { MWCNT oxidized in } \mathrm{HNO}_{3}(5 \mathrm{M}) \\
\text { yarns }\end{array}$ & $969\left(1.03 \times 10^{-3}\right)$ & - & & & & Li et al., 2007 \\
\hline $\mathrm{HSO}_{3} \mathrm{Cl}$-doped SWCNT yarns & $2.9 \times 10^{4}\left(3.4 \times 10^{-5}\right)$ & $2.2 \times 10^{3}$ & $6.6 \times 10^{3}$ & 1.3 & & Behabtu et al., 2013 \\
\hline I-doped SWCNT yarns & $5.0 \times 10^{4}\left(3.4 \times 10^{-5}\right)$ & $\sim 3.57 \times 10^{3}$ & & 1.4 & & Behabtu et al., 2013 \\
\hline $\mathrm{HSO}_{3} \mathrm{Cl}$ and I-doped SWCNT yarns & $5 \times 10^{4}\left(2 \times 10^{-5}\right)$ & $4.18 \times 10^{3}$ & & 1.2 & & Behabtu et al., 2013 \\
\hline $\begin{array}{l}\text { Thermally oxidized and chemically } \\
\text { etched DWCNT yarns }\left(\mathrm{H}_{2} \mathrm{O}_{2} 30 \%\right) \text {, } \\
\left.\mathrm{HCl}_{(\mathrm{c})} \text {, then } \mathrm{H}_{2} \mathrm{SO}_{4(\mathrm{c})}\right)\end{array}$ & $2 \times 10^{4}\left(5 \times 10^{-5}\right)$ & $\sim 7.1 \times 10^{3}$ & $\sim 10^{4}-10^{5}$ & 0.28 & & Zhao et al., 2011 \\
\hline $\begin{array}{l}\text { as above additionally I-doped } \\
\text { DWCNT yarns }\end{array}$ & $6.7 \times 10^{4}\left(1.5 \times 10^{-5}\right)$ & $1.96 \times 10^{4}$ & & 0.33 & & Zhao et al., 2011 \\
\hline \multicolumn{7}{|l|}{ Doped graphene fibers: } \\
\hline $\mathrm{FeCl}_{3}$-doped GR fibers & $0.77 \times 10^{5}\left(1.3 \times 10^{-5}\right)$ & $4.74 \times 10^{3}$ & & $\sim 1.625$ & & Liu et al., 2016 \\
\hline $\mathrm{Br}_{2}$-doped GR fibers & $1,5 \times 10^{5}\left(6.7 \times 10^{-6}\right)$ & $9.23 \times 10^{3}$ & & $\sim 1.625$ & & Liu et al., 2016 \\
\hline K-doped GR fibers & $2.24 \times 10^{5}\left(4.5 \times 10^{-6}\right)$ & $1.38 \times 10^{4}$ & & $\sim 1.625$ & & Liu et al., 2016 \\
\hline Au-coated GR fibers & $2.86 \times 10^{2}\left(3.50 \times 10^{-3}\right)$ & $6.81 \times 10^{2}$ & & 0.42 & & Yun et al., 2017 \\
\hline Ag-doped GR fibers & $9.3 \times 10^{2}\left(1.08 \times 10^{-3}\right)$ & & $7.1 \times 10^{3}$ & & & Xu Z. et al., 2013 \\
\hline $\mathrm{N}$-doped rGO fibers & $6.94 \times 10^{1}\left(1.44 \times 10^{-2}\right)$ & & & & & Liu Q. et al., 2020 \\
\hline N-doped GR fibers & $9.51 \times 10^{-1}(1.05)$ & - & - & - & & Chong et al., 2019 \\
\hline
\end{tabular}

The symbol refers to values calculated from the data provided by authors. SWCNTs: single-walled carbon nanotubes; DWCNTs: double-walled carbon nanotubes; MWCNTs: multi-walled carbon nanotubes; GR: graphene; GO: graphene oxide; rGO: reduced graphene oxide. 
mismatch (i.e., alignment of the 6-member rings within adjacent $\mathrm{CNTs}$ ) and a large diameter ratio among two intersecting carbon nanotubes, an increased resistance of three orders of magnitude was measured at the junction region (c.a. $M \Omega$ compared with c.a. $\mathrm{k} \Omega$ measured far from the crossing point) (Barnett et al., 2019). The authors also showed that, in agreement with the unit cell dimensions (Meunier et al., 1999), a clear periodic dependence of the resistance on the periodicity of $2-3 \AA$ was obtained. These and other concerns stimulate the realization of macroscopic assembles of nanocarbons to form fibers, even though in reality the availability of infinitely pure and selected "building blocks" still requires development, especially from a practical point of view. Moreover, the overall properties of the assembled fibers are determined in a large extent by composition, morphology and structure (i.e., orientation and type) of their basic units and their interconnection characteristics, which are controlled by the precursor type and preparation procedure (Fang et al., 2020).

The fibers containing carbon nanostructures can have a very wide range of electrical conductivity. In principle, both CNTs and graphene exhibit semimetal characteristics and their conductivities are few-orders of magnitude higher than that of their macroscopic assemblies, which behave as semiconductors (Li et al., 2007; Fang et al., 2020), thus suggesting that the contact resistance at the interface plays a significant role. Commonly, the temperature dependence with electrical properties indicates that the conductivity of all-carbon fibers increases from low to room temperature (semiconducting behavior) (Li et al., 2007; Dini et al., 2019, 2020; Fang et al., 2020), but with lower dependency than carbon counterparts (i.e., graphite, graphite fibers). In graphene and CNT fibers the electron transport properties are dominated by hopping mechanism (Li et al., 2007; Fujita and Suzuki, 2010; Liu et al., 2016). Electrical transport properties, investigated by Dini et al. (2019) in a large range of temperature $(3-350 \mathrm{~K})$, indicated that resistivity decreases exponentially below $70 \mathrm{~K}$ due to the prevailing intercontact effects among CNTs, while above $70 \mathrm{~K}$ the resistivity decreases linearly and the intrinsic CNT resistivity properties prevail. Interestingly, the same authors estimated the resistivity in their CNT bundle to be $\sim 8 \times 10^{-4} \Omega \cdot \mathrm{cm}\left(1.25 \times 10^{3} \mathrm{~S} / \mathrm{cm}\right)$, which was very close to that of CNT yarns $\left(1.1 \times 10^{-3} \Omega \cdot \mathrm{cm}\right.$, corresponding to $9.1 \times 10^{2} \mathrm{~S} / \mathrm{cm}$ ) at room temperature and they concluded that the CNT bundle resistivity is the limiting factor in the CNT fibers. In the same experiments, it was also observed at room temperature that the electrical transport was not affected by densification of CNT fibers and the contacts between CNTs.

As reported by some authors, properties of carbon ropes made of individual CNTs or graphene sheets, can be increased by the heat treatment. Xin et al. (2019) have precisely determined the effect of thermal heating up to $2850^{\circ} \mathrm{C}$ for graphene fibers, but the same conclusion can be remarked for CNT fibers (Dini et al., 2020). Wang et al. (2020) reported that when fibers were subjected to Joule heating a significant enhancement of mechanical and electrical properties can be observed. The authors described the increase in properties with the formation of chemical bonding of individual CNTs by means of 1,3,5tris $(2$ '-bromophenyl) benzene $(2 \mathrm{TBB})$ acting as a cross-linking agent. Crosslinking with $2 \mathrm{TBB}$ increased the tensile strength of fibers by $47 \%$ and enhanced the electrical conductivity by a factor of c.a. 100 (from 160 up to about $10200 \mathrm{~S} / \mathrm{m}$ ) after passing a current through the fiber, with the consequent localized heating at the more resistive CNT junctions. The selective thermal dehalogenation of the organic precursor, for a fact, may lead to the covalent bonding formation. In another recent paper, Hada et al. (2019) reported that the Joule annealing (c.a. $1800^{\circ} \mathrm{C}$ ) of $\mathrm{CNT}$ fibers of c.a. $20 \mu \mathrm{m}$ in diameter, caused the interfacial amorphous carbon phase to be converted into graphene fragments between adjacent CNTs. Liu et al. (2012) described the $\mathrm{CO}_{2}$ laser induced annealing of CNT fibers under vacuum conditions $\left(10^{-6}\right.$ Torr). The laser light absorbed from the (black) CNTs, may promote a local heating (Cesano et al., 2013) and similar to a conventional heat treatment, leads to the reduction of defects with the consequent increment of the mechanical and electrical properties.

On the other hands, the addition of graphene flakes within a CNT wire to constitute a hybrid composition has been shown to increase the electrical conductivity, current-carrying capacity (or ampacity, which can be defined as the maximum current in amperes, that a conductor can carry continuously under the conditions of use and without exceeding its temperature rating) and doping properties (Li and Pandey, 2015; Lepak-Kuc et al., 2019). Besides the remarked relevance of the graphene flake characteristics, of the fiber purity and of the solvent properties, the authors explained that graphene flakes constitute effective bridges by means of a theoretical model. Such bridges create Fermi level states inside the CNTs bands, with the consequent increase of current and electrical conductance in the system, while doping can enhance the conductance of the hybrid assembly. The doping of the carbon and the related electrical conductivity is discussed in the next section.

Along with CNT fibers, some important concepts for achieving higher electrical properties can be summarized. Firstly, metallic nanotubes may exhibit ballistic transport, but the defects and impurities (i.e., catalyst and amorphous carbon on the surface) interrupt the electron transport and promote a random scattering with the consequent increase of the contact resistance at the interface between CNTs (Lekawa-Raus et al., 2014b). Secondly, the choice of metallic SWCNTs, DWCNTs or a few walled CNTs together with the annealing at the high temperature (higher than c.a. $2000^{\circ} \mathrm{C}$ ) of the assembled fibers play a significant role in targeting the high conductivity (Wang et al., 2014). Lastly, the control over structure and defects of fibers (i.e., voids, pores, tube misalignment) is necessary to further mitigate the contact resistance (Zhang et al., 2019). Considering the different methods of the CNT fiber preparation, we can conclude that among the best electrical conductivities of CNT yarns are obtained by the wet spinning techniques of SWCNTs and DWCNTs $\left(\sim 9 \times 10^{4} \mathrm{~S} \cdot \mathrm{cm}^{-1}\right)$ (Tsentalovich et al., 2017). However, in some of these preparations, CNTs are often in the presence of strong acids, raising the doubt that acid doping could be the main responsible for the high fiber conductivity. Along with the other CNT fiber preparation methods, CNT can be directly spun into fibers from floating catalyst CVD or fixed-bed CVD processes and the observed conductivity is of the order of $\approx 10^{3}-10^{4} \mathrm{~S} \cdot \mathrm{cm}^{-1}$ (Liu et al., 2012; Lekawa-Raus et al., 2014a) with best values when the densification is optimized (e.g., rolling under pressure) (Wang et al., 2014). 
As far as graphene fibers are concerned, some important concepts for achieving higher electrical properties can be summarized. Firstly, polymer based-graphene fibers exhibit a limited conductivity. Secondly, the heating temperature as high as $\approx 2000^{\circ} \mathrm{C}$ or more is necessary to have a significant effect on the conductivity (Xin et al., 2019). Lastly, due to the polycrystalline nature of the graphene domains and the three-dimensionality of the microfiber backbone, the control over the orientation of graphene sheets and concentration of defects (i.e., from the macroscale to the atomic scale: random wrinkles at the surface, core-shell and along axis inhomogeneities, voids/porosity, $\mathrm{sp}^{3}$ $\mathrm{C}$ terminations at the boundaries) is necessary ( $\mathrm{Xu}$ et al., 2016). Surprisingly, Liu et al. (2017) assembled macroscopic graphene fibers intercalated with $\mathrm{Ca}$ ( $\mathrm{Ca} 10 \mathrm{wt} \%)$. At very low temperature $(\sim 11 \mathrm{~K})$ the Ca-doped fibers exhibited a superconducting transition.

All the previous considerations are valid with direct current (DC), while for the conductivity in alternating current (AC) other factors should be also considered, because the signal transport through a conductor becomes difficult at the high frequency, due to skin and proximity effects. Skin effect occurs in a conductor at high frequency with a distribution of the current density, leading to a higher resistance. The alternating flux in a conductor, caused by the current of the other near conductors, results an apparent increase in the resistance and is called proximity effect. Theoretically, a single SWCNT should be unaffected by skin effect. It is expected that the tubular nature at the nanoscale of CNTs should mitigate both the skin and proximity effects, thus enabling a high frequency transport superior to typical metals (Lekawa-Raus et al., 2014b, 2017). However, the literature on this subject is still very limited.

\section{THE ROLE OF CHEMISTRY TO INCREASE THE CONDUCTIVITY}

In a recent study, Lee J. et al. (2019) reported an optimized method, in which the wet spinning of CNTs in chlorosulfonic acid (CSA) followed by stretching of the fiber in a coagulation bath, allows to rearrange entangled CNTs and to increase the alignment of nanotubes. The authors reported that the highly packed and aligned CNTs confer high mechanical and electrical properties to the fiber (among the record observed for the undoped CNT fibers reported in Table 1). However, the electrical properties of the conductors seem to be limited by the multidomain structure of the assembled CNTs/graphene sheets, which are regularly and continuously aligned and reoriented along the axial direction (Xu and Gao, 2015). Molecular assembly strategies alone (Aboutalebi et al., 2014; Kou et al., 2017) would not allow to surpass the electrical conductivity of metals. On the other hand, it is generally observed that the infiltration with polymers resulted in a significant decrease in electrical conductivity (Lu et al., 2012).

\section{Beyond the Conductivity of Carbon Yarns and Fibers: Doping and Intercalation}

The doping paradigm to increase the electrical properties of carbon-based conductors is not new. Since the last century the graphite intercalation compounds (GICs) with halogens, alkali compounds were studied (Hennig, 1952; Ottmers and Rase, 1966). It was found that a remarkable variation of the free-carrier concentration allows the enhancements of the electrical, thermal and magnetic properties of the host material (Dresselhaus and Dresselhaus, 2002). Most of the recent studies on conductors based on doped carbons have examined the case of carbon nanotube fibers, while the literature on graphene fibers appears moderately more limited.

Randeniya et al. (2010) showed that metal nanoparticles $(\mathrm{Cu}$, $\mathrm{Au}, \mathrm{Pd}, \mathrm{Pt})$ doped CNTs are able to reach metal-like electrical conductivities $\left(2-3 \times 10^{5} \mathrm{~S} \mathrm{~cm}^{-1}\right)$ that are three orders of magnitude higher than the uncoated carbon fiber backbones. According to this, the approach to improve specific conductivity suggests that alkali metals ( $\mathrm{Li}, \mathrm{Na}, \mathrm{K}$ ) act as n-dopant, while halogen $\left(\mathrm{Cl}_{2}, \mathrm{Br}_{2}, \mathrm{I}_{2}\right)$, oxidants $\left(\mathrm{HNO}_{3}, \mathrm{SOCl}_{2}, \mathrm{H}_{2} \mathrm{O}_{2}\right), \mathrm{FeCl}_{3}$, $\mathrm{PtCl}_{4}$ and $\mathrm{MoCl}_{5}$ as p-dopants (Liu et al., 2016; Liu Y. et al., 2020; Zhang et al., 2019). Other used dopants with molecular structure are $\mathrm{H}$-carbazole ( $\mathrm{p}$-dopant) and phosphine derivatives (n-dopants) (Lee T. et al., 2019). A general result of the doping process is the change in the color close to the saturation percentages: pure all-carbon fibers are silver gray (i.e., graphite) or black (i.e., assembled CNTs), while $\mathrm{FeCl}_{3}$ - and $\mathrm{Br}_{2}$-doped graphene fibers show dim luster appearance $(15 \%$ and $10 \%$ of doping, respectively), while K-doped fibers evolve from silver gray to bright-golden yellow (26\% of doping) (Liu et al., 2016), due to Drude plasma frequency shifting into visible range (Fischer, 2006) together with the increasing concentration of carriers and in analogy with graphite intercalation compounds (Dresselhaus and Dresselhaus, 2002) (i.e., charge transfer into the antibonding $\pi^{*}$-band or from the bonding $\pi$-band thus acting as donor or acceptor guests, respectively Clancy et al., 2018). The increased carrier density and the mobility in doped fibers may allow a higher electrical conductivity, which was found to show the same temperature dependency with small variation than pure all-carbon fibers. All these elements imply that the band structure evolves from a two-carrier semimetal model of graphite to onecarrier free-electron-like metal model with the increasing of the dopant concentration (Fischer and Thompson, 1978).

Recent studies suggest that the electrical properties increase with the amount of dopant due to the shifting of the Fermi level, although there is an intrinsic limit of the doping loading (Zhang et al., 2019). Zhao et al. (2011) reported the preparation of I-doped CNT fibers with electrical conductivity as high as $6.7 \times 10^{4} \mathrm{~S} / \mathrm{cm}$. With the doping with iodine, polyiodide chains are formed. Together with $\mathrm{I}_{3}^{-}$and $\mathrm{I}_{5}^{-}$species, the hole concentration was found to be one order of magnitude higher (from c.a. $1.65 \times 10^{18} \mathrm{~cm}^{-3}$ to $2.90 \times 10^{19} \mathrm{~cm}^{-3}$ ) (Zhang S. et al., 2017). Together with improved carrier mobilities, a similar increased charge carrier concentrations (holes) (i.e., p-type doping) of $2.69 \times 10^{20} \mathrm{~cm}^{-3}$ and $1.43 \times 10^{20} \mathrm{~cm}^{-3}$ (from $3.96 \times 10^{19} \mathrm{~cm}^{-3}$ of pure graphene) for $\mathrm{Br}_{2}$ - and $\mathrm{FeCl}_{3}$-doped graphene, while $\mathrm{K}$-doped graphene showed n-type characteristics (i.e., carrier type: electron) with a much higher carrier concentration $\left(2.07 \times 10^{21} \mathrm{~cm}^{-3}\right)$ that is a value closer to the carrier mobility value of metals (c.a. $10^{22} \mathrm{~cm}^{-3}$ ), as obtained with Hall effect measurements in a van der Pauw geometry by 

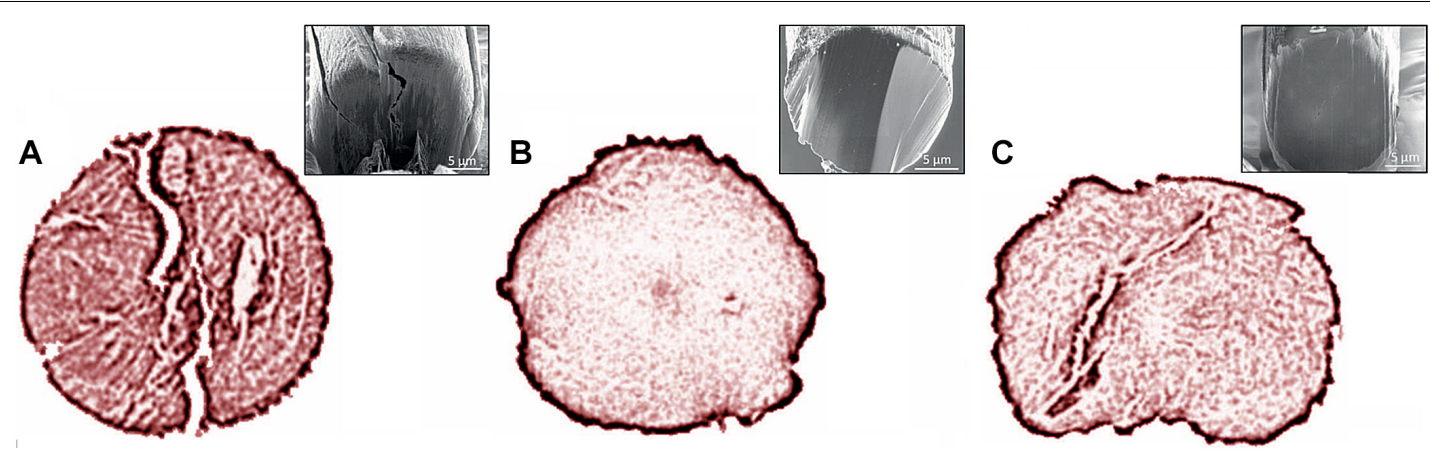

FIGURE 6 | Phase contrast X-ray computed tomography images of CNT fiber cross-sections for three type of fibers prepared by twisting (A) thick, (B) thin, or (C) by solution-spinning from coagulation bath. SEM images of the same fibers are reported in the insets. Adapted from Headrick et al. (2018) with permission from Wiley-VCH.

Liu et al. (2016), Liu Y. et al. (2020). In another paper, Zhang and Fahrenthold (2019) reported the highest doping density with $\mathrm{K}$ atoms on the graphene surface as obtained by adding one dopant per two carbon hexagons, thus giving a structure corresponding to $\mathrm{KC}_{8}$ (Zhang and Fahrenthold, 2019), while 15\% and $10 \%$ are nearly the saturation doping percentages for $\mathrm{FeCl}_{3}$ and $\mathrm{Br}_{2}$, respectively (Liu et al., 2016). Along the dopant series, $\mathrm{K}$ and I appear to be the most promising, but they have been also found somehow instable in air and the fiber structure may undergo an immediate degradation by moderate temperature exposures. The preparation of iodine-doped DWCNT cables with electrical resistivity achieving $10^{-5} \Omega \cdot \mathrm{cm}\left(6.7 \times 10^{4} \mathrm{~S} / \mathrm{cm}\right)$ has been reported by Zhao et al. (2011). The authors reported that cables of different diameters ranging from 4 to $45 \mu \mathrm{m}$ display high current carrying capacity $\left(10^{9}-10^{10} \mathrm{~A} / \mathrm{cm}^{2}\right)$, which is of three orders of magnitude larger than those of metals. In the paper, DWCNT yarns with smaller diameter were found to have larger resistivity compared to larger diameter fibers, thus indicating the role played by voids, other defects and skin effects on the conductivity. The electrical conductivity boosted to a metallic level has been observed for doped-graphene and carbon nanotube fibers (Xu and Gao, 2015; Fang et al., 2020). In a recent paper, Lee T. et al. (2019) have shown the fabrication of flexible thermoelectric generators based on CNT fibers. Interestingly, the authors reported that by optimizing the alignment degree of CNTs and doping the nanotubes with $\mathrm{H}$-carbazole and phosphine derivatives ( $\mathrm{p}$ - and $\mathrm{n}$-dopant, respectively) the carrier mobility increased with an improvement of the power factor of the generator. In another recent paper, Hada et al. (2019) reported the thermoelectric application of Joule annealed CNT yarns undoped and doped with polyethylenimine (PEI). Surprisingly, Joule annealed undoped and PEI doped CNT fibers exhibit remarkable Seebeck coefficients $(+100 \mu \mathrm{V} / \mathrm{K}$ and $-100 \mu \mathrm{V} / \mathrm{K}$, respectively), which are values close to those of inorganic thermoelectric materials. Furthermore, Joule heating of the CNT yarns after PEI doping (n-dopant) was found to increase the conductivity of the yarns of about three times $\left(10^{5} \mathrm{~S} / \mathrm{m}\right)$. Liu Y. et al. (2020) have recently reported the intercalation of graphene films by means of $\mathrm{MoCl}_{5}$. The room temperature conductivity of the film reached the record value for the graphene series of $1.7 \times 10^{-5} \mathrm{~S} \mathrm{~cm}^{-1}$.
Interestingly, the authors reported a significative dependence of the conductivity with the doping amount together with a long-term stability under environmental conditions ( $>1$ year), thermal $\left(140^{\circ} \mathrm{C}\right)$ and chemical resistance against some $\mathrm{MoCl}_{5}$ solvents (acetone, carbon tetrachloride, ethanol and $\mathrm{H}_{2} \mathrm{O}$ ).

In summary, the chemical doping has the potential to improve the thermal and electrical conductivities of CNT and graphene fibers. Notwithstanding the increase observed for doped systems, the electrical conductivity of carbon yarns becomes comparable or higher than that of metal filaments. Another advantage of carbon-based filaments over metallic filaments is that they allow a remarkable chemical resistance. However, the temperature and time stability under working conditions still needs further investigations and improvements.

\section{A-Few Characterization Techniques}

3D X-ray tomography (3D XRT) is a non-destructive method, which now offers a spatial resolution down to $\sim 10$ and $50 \mathrm{~nm}$ in synchrotron and lab facilities, respectively. The method could be applied to examine structure, porosity, cracks phase distribution, external habit of fibers (Figure 6), thus highlighting also interfaces within the structure of the assembled fiber (Headrick et al., 2018).

X-ray scattering techniques can provide useful insights of the fiber scaffold and of its components. Although, from X-ray diffraction (XRD) patterns, the structure of CNTs appears close to those of graphitic materials due to their intrinsic nature, 3D XRD analysis can further provide the fiber crystallite sizes along both, longitudinal and transversal directions (Xin et al., 2019). In addition, XRD measurements can be also utilized to study the nature of intercalated compounds (e.g., doping) with the appearance of peaks corresponding to the d-spacings larger than $0.334 \mathrm{~nm}$ (002) peak of graphite. For example, Zhou et al. (2017) reported the occurrence of a series of peaks indexed as $(00 l)$ with d-spacings of $0.53 \mathrm{~nm}$ and of $0.43 \mathrm{~nm}$ in K-doped graphene film intercalation compounds. The same $(00 l)$ peak series was identified together with a shifting toward lower $2 \theta$ values (Liu et al., 2016) (Figure 7A). The same authors reported also interlayer spacings of $0.34 \mathrm{~nm}$ and of $0.49 \mathrm{~nm}$ for $\mathrm{Br}_{2}$ - and $\mathrm{FeCl}_{3}$-doped graphene fibers, respectively. Ca-doped 

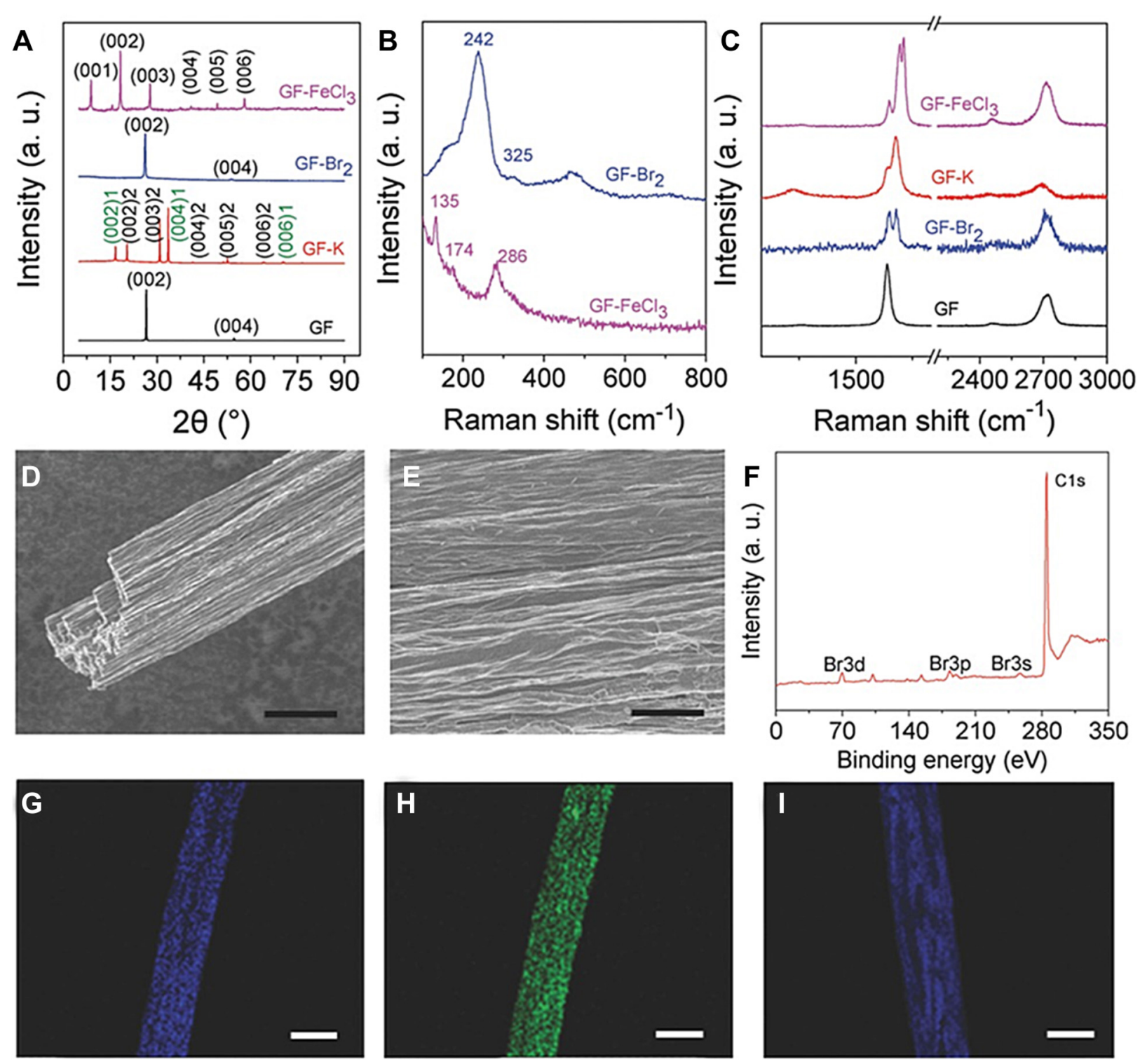

FIGURE 7 | (A) XRD patterns of the pure and doped graphene fibers. Raman spectra of: (B) doped graphene fibers in the lower wavenumber region and (C) pure and doped graphene fibers in the higher wavenumber region; (D,E) SEM images of the graphene fibers obtained at different magnification (Scalebars: $20 \mu \mathrm{m}$ in $\mathbf{D}$ and $5 \mu \mathrm{m}$ in E); (F) XPS spectrum of the Br-doped graphene fibers; and (G-I) Elemental mapping images of iron, chlorine, and potassium doped graphene fibers (Scalebars are $50 \mu \mathrm{m})$. Reproduced from Liu et al. (2016) with permission from Wiley-VCH.

carbon-assembled fibers was reported to show a series of $(00 l)$ reflections with d-spacings of $0.45 \mathrm{~nm}, 0.34 \mathrm{~nm}$, and $0.23 \mathrm{~nm}$ indexed as (003), (002), and (006) (Liu et al., 2017). Wideangle X-ray scattering (WAXS) technique can be informative about the structure and orientation degree along the fiber axis (Xu et al., 2012, 2016; Alemán et al., 2015). Small-angle X-ray scattering (SAXS) was performed by Xu et al. (2012, 2019) to investigate the size and shape confinements in the fiber of the carbon building blocks and optimize the fluid dynamics in the wet-spinning of the graphene fiber fabrication (2D SAXS configuration). Lamellar structural information is of particular interest when GO or liquid crystals are used in presence of nematic, lamellar and chiral compounds (Kumar et al., 2017; Clancy et al., 2018; Fang et al., 2020). This fact is however not surprisingly, due to the familiar concept in polymer science.

Raman spectroscopy is one of the main analytical techniques that provide a detailed picture about chemical structure, phase, crystallinity and molecular interactions, not only of the CNTs and graphene sheets, but also of the final assembled fiber. A detailed description of CNT and graphene Raman features goes beyond the scope of this review and can be found elsewhere (Dresselhaus et al., 2010; Saito et al., 2011; Eckmann et al., 2012; Jain et al., 2017; Groppo et al., 2018). Among all fingerprints, 
the presence of the D-band at about $1350 \mathrm{~cm}^{-1}$ comes from double resonance Raman effect corresponding to disordered carbon structure, while the G-band (c.a. $1580-1600 \mathrm{~cm}^{-1}$ ) is associated with stretching modes of the $\mathrm{C}$ - $\mathrm{C}$ bonds in graphitic materials commonly found in all $\mathrm{sp}^{2}$ carbons. This spectral feature associated with the curvature and appearing similar for nanotubes and graphene, reveals distinct characteristics allowing to distinguish a carbon structure from another one (i.e., multiple peaks in SWCNTs, a strong peak at c.a. $1582 \mathrm{~cm}^{-2}$ in graphene, etc.). A D-band overtone centered at about $2700 \mathrm{~cm}^{-1}$ and called $2 \mathrm{D}$ band can be found. The evolution of the $2 \mathrm{D} / \mathrm{D}$ intensity ratio can be used to determine the number of the stacked graphene layers (Papageorgiou et al., 2017). Furthermore, an additional feature is found in SWCNTs known as radial breathing mode (RBM) of SWCNTs. This fingerprint can also provide a detailed description of the type, structure and diameters of the nanotubes. Interestingly and very recently, Park Y. et al. (2019) reported a reinterpretation of SWCNTs' Raman fingerprints considering also opened tubular graphene structures (c.a. $2 \mathrm{~nm}$ in diameter). The authors associated the observed RBM band with a convolution of "localized RBM" (c.a. $170 \mathrm{~cm}^{-1}$ ) and RTM (radial-tangential mode) (c.a.190 $\mathrm{cm}^{-1}$ ), together with the $\mathrm{D}$ mode (c.a. $1350 \mathrm{~cm}^{-1}$ ), originated from the edge defects of graphene and the $\mathrm{G}^{-}$mode (c.a. $1570 \mathrm{~cm}^{-1}$ ) appearing red shifted from the $\mathrm{G}^{+}$peak (c.a. $1590 \mathrm{~cm}^{-1}$ ) and with a different shape (due to a curvature effect). Notably, the alignment of CNT fibers can be assessed by polarized Raman measurements (Kou et al., 2017; Lee J. et al., 2019; Xin et al., 2019; Zhang et al., 2019). An increased $\mathrm{I}_{\mathrm{G} \|} / \mathrm{I}_{\mathrm{G} \perp}$ (G-peak intensity ratio obtained for the polarization parallel to that of the polarization perpendicular to the fiber axis, respectively) is an indication of the increased domain alignment. Raman spectroscopy is also worth of a special mention in the case of doped systems. As a matter of fact, the G band upshift is usually observed in doped CNTs and graphene also when the structural integrity of the structure is preserved. The reason is that G-band position, very sensitive to charge doping, shifts the Fermi level left from the neutrality point (Liu et al., 2016). Liu et al. (2016) have shown a double peaks (c.a. $1616 \mathrm{~cm}^{-1}$ and $1626 \mathrm{~cm}^{-1}$ ) of the G-band for $\mathrm{FeCl}_{3}$ doped graphene fibers. The author observed a similar G-band upshifting of c.a. $23 \mathrm{~cm}^{-1}$ and $25 \mathrm{~cm}^{-1}$ for $\mathrm{K}$ - and $\mathrm{Br}_{2}$-doped graphene fibers, respectively. Liu et al. (2016) showed Raman spectra with upshifted $G$ peaks, together with an additional peak at c.a. $242 \mathrm{~cm}^{-1}$, which corresponds to bromine anions. Additional peaks at $135 \mathrm{~cm}^{-1}, 174 \mathrm{~cm}^{-1}$, and $286 \mathrm{~cm}^{-1}$ can be found to verify the successful doping with $\mathrm{FeCl}_{3}$ (Liu et al., 2016) (Figures 7B,C). 2D band downshifting can be observed after doping. This fact arises from the not negligible lattice expansion occurred after doping.

Electron microscopies (scanning and transmission electron microscopy: SEM and TEM, respectively) are typically adopted techniques to investigate the morphology, structure and twisting properties of the assembled fibers (Aboutalebi et al., 2014; Zeng et al., 2018). Visual inspections of the fiber backbone, allows to identify multiscale defects, which include rough surface with wrinkles, degree of homogeneity of the structure, presence of larger pores and boundary regions at lower resolution (SEM), crystallinity and defects of CNTs and of graphene sheets, including vacancy defects, dislocation edges, stacking faults, grain boundaries and other features (HR-TEM), as well documented in some papers (Behabtu et al., 2013; Kou et al., 2014, 2017; Liu et al., 2016; Papageorgiou et al., 2017; Zeng et al., 2018; Fang et al., 2020; Yin et al., 2020) (Figures 7D-I). Furthermore, elemental mapping images can demonstrate not only the doping, but also the element distributions along the fiber. Focused ion beam (FIB) milling can be used to cut down a fiber with sections perpendicular and parallel to the axis of the fiber. Such sections can be directly SEM imaged to reveal the yarn structure and correlate changes in morphology and structure with properties (Sears et al., 2010).

X-ray photoelectron spectroscopy (XPS) measurements can be informative of the chemical state, and of the electronic state composition of the elements at the surface of fibers. Together with the characteristic peaks of both graphene and CNTs at $284.5 \mathrm{eV}$ (C-C bonds) and $285.7 \mathrm{eV}$ ( $\mathrm{C}=\mathrm{C}$ bonds), minor peaks at c.a. $286.2 \mathrm{eV}$, c.a. $287.8 \mathrm{eV}$, and c.a. $289.0 \mathrm{eV}$ can be observed, due to the presence of $\mathrm{C}-\mathrm{O}, \mathrm{C}=\mathrm{O}$, and $\mathrm{O}-\mathrm{C}=\mathrm{O}$ functional groups, respectively. It is also observed that the intensities of oxygen-reach peaks increased with the oxidation time (Park H. et al., 2019). The incorporation of other dopants into CNT and graphene fibers can be also determined by XPS. The high-resolution spectra indicated $\mathrm{C}-\mathrm{N} \mathrm{sp} \mathrm{s}^{2}$ and $\mathrm{sp}^{3}$ bonding at $286.1 \mathrm{eV}$ and $288.2 \mathrm{eV}$, respectively (Ryu et al., 2015), C-Br at $286.9 \mathrm{eV}$ together with peaks at $257.2 \mathrm{eV}, 182.9 \mathrm{eV}$, and $69.6 \mathrm{eV}$ corresponding to $\mathrm{Br} 3 \mathrm{~s}, \mathrm{Br} 3 \mathrm{p}$, and $\mathrm{Br} 3 \mathrm{~d}$.

Often the assembled fibers contain pores among nanotubes or sheets due to the microcrystalline nature of the carbon building blocks. A porosity would be beneficial for electrochemical and sensing applications (Xu et al., 2012; Cai et al., 2015; Fan et al., 2016; Park H. et al., 2019), but can limit the properties for electrical transport applications (Miao, 2011). For this reason, it would be convenient to investigate the porosity of the fiber by means of sorption techniques. Zeng et al. (2018) have obtained microporous CNFs with variable surface area (from c.a. $850 \mathrm{~m}^{2} \mathrm{~g}^{-1}$ to c.a. $7 \mathrm{~m}^{2} \mathrm{~g}^{-1}$ depending on the duration of the CVD process), due to the highly defective nature caused by $\mathrm{NH}_{3}$ etching. The authors observed an increase of the electrical conductivity with the densification of the fiber of one order of magnitude.

Contact angle measurements can provide important findings on the fiber-liquid interactions (Zhang L. et al., 2017; Zeng et al., 2018). The non-polar and polar surface energy components can be obtained and other wetting parameters (work of adhesion, spreading coefficient and wetting tension) can be predicted.

In most of the synthesis methods to obtain nanocarbons a material with a large variety of properties is produced. Such material contains also catalyst nanoparticles, amorphous carbon and other side-products. There are several methods to investigate carbon yarns, before/after fiber production and after the doping step. Among all, termogravimetric analysis (TGA) can be used to verify purity and thermal stability of the fibers (Lepak-Kuc et al., 2018; Lee J. et al., 2019). Due to the higher chemical reactivity in air, a decrease in weight in the $250-400^{\circ} \mathrm{C}$ range may be related to amorphous carbon elimination (i.e., from CNTs). The oxidation 
A
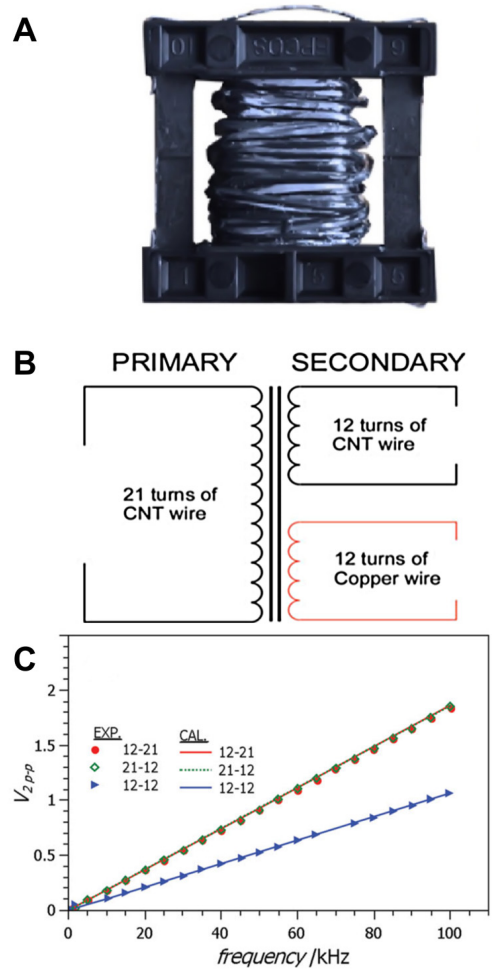

D

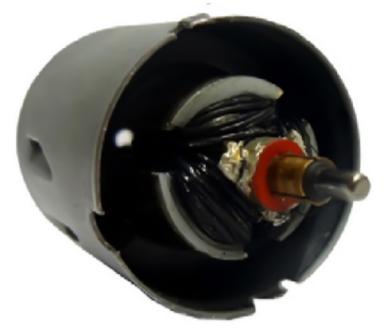

E
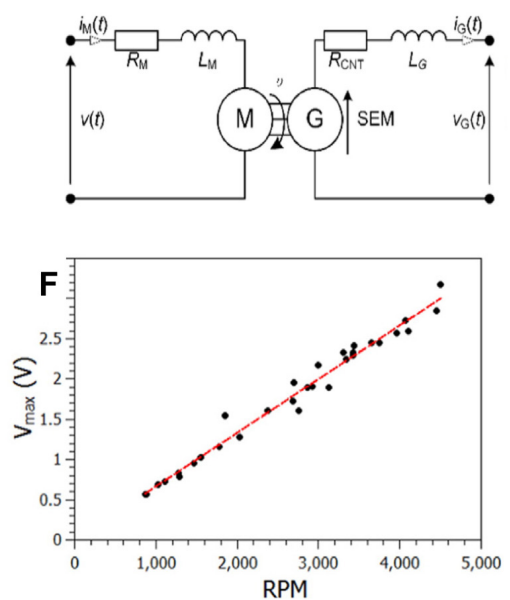
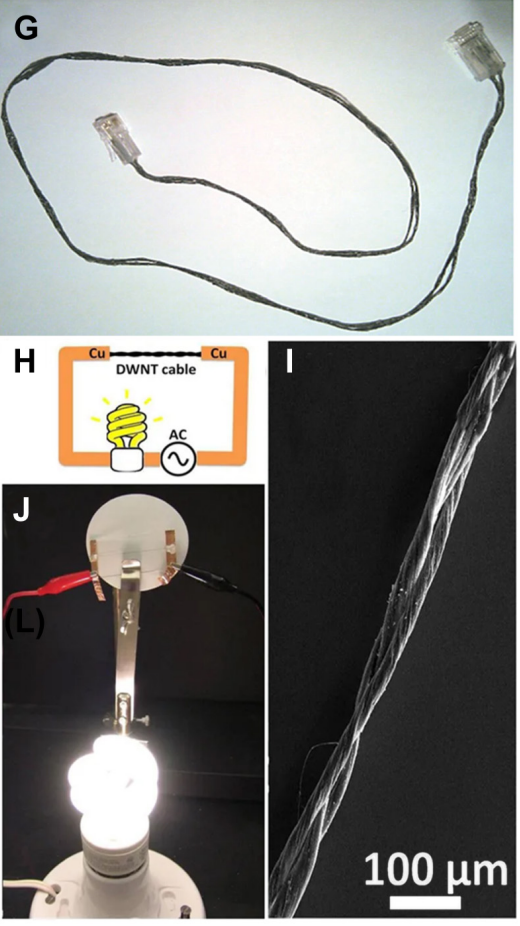

FIGURE 8 | (A) Photo, (B) characteristics of the primary and of the secondary windings, and (C) electrical performances of the CNT-fiber transformer. (D) Photo, (E) schematics of the circuit, and (F) electrical performances of the CNT-fiber shunt generator. (G) image of the ethernet cable made of CNT wires, (H) scheme, (I) SEM image, and (J) image of an I-doped CNT cables exceeding the specific electrical conductivity of metals. A,D,E,F: reproduced from Lekawa-Raus et al. (2017) with permission from Elsevier. B,C: reproduced from Kurzepa et al. (2014) with permission from Wiley-VCH. Panel (G) adapted from Lekawa-Raus et al. (2014b). Panels (H-J) adapted from Zhao et al. (2011) under the Creative Commons CC BY license.

of more graphitized structures is, for a fact, expected to occur above $500^{\circ} \mathrm{C}$ in air. The loading of metal catalyst and of the inorganic supports $\left(\mathrm{Al}_{2} \mathrm{O}_{3}, \mathrm{SiO}_{2}\right)$ of the initial carbon materials and/or their presence in the final fibers can be determined. If the fiber is undoped, the residue of the thermal treatment performed in air can be easily associated with the inorganic content of the catalyst and of the metal oxide support. A decrease in the stability of materials with a reduction of the oxidation temperature can be also observed after an acid treatment (e.g., $\mathrm{H}_{2} \mathrm{SO}_{4}, \mathrm{HClO}_{4}$ ) of purification or doping. Notice that, in general the strongly oxidized carbon materials are more reactive to the thermal treatments (Cravotto et al., 2011).

\section{FRONTIERS OF THE CURRENT TECHNOLOGY}

Behabtu et al. (2013) have demonstrated several applications of CNT fibers. Interestingly, the authors showed a light-emitting diode (LED) suspended and electrically contacted by two CNT fibers (24 nm in diameter) loaded with $30 \mathrm{~mA}$ current $\left(6.6 \times 10^{3}\right.$ $\mathrm{A} / \mathrm{cm}^{2}$ as a current density). More interestingly, the same authors illustrated a field-emitting device fabricated with a CNT fiber working as a cathode. An emitted current density of $5.8 \times 10^{3}$
$\mathrm{A} / \mathrm{cm}^{2}$ was reported $(3.6 \mathrm{~mA}$ from a CNT fiber with a diameter of $9 \mu \mathrm{m})$ at $0.86 \mathrm{~V} / \mu \mathrm{m}$ placed at $1 \mathrm{~mm}$ from the anode. Surprisingly, Kim et al. (2017) presented an energy harvester, made of two twisted carbon nanotube yarns, which converts electrical from mechanical energy, both torsional and tensile motions, without the need of an external bias voltage. By stretching the coiled yarns $250 \mathrm{~W} / \mathrm{kg}$ can be generated when cycled up to 30 hertz. These kinds of devices could be used perhaps in the sea to harvest wave energy, as well as with thermally driven artificial muscles to convert temperature fluctuations to electrical energy. In other papers, Uddin et al. (2014) and Yan et al. (2014) have shown a three-dimensional dye-sensitized solar cell (DSSC) wire by using $50 \mu \mathrm{m}$ diameter CNT yarns as working electrodes. Beside other advantages (flexibility, mechanical resistance, electrically and catalytically active), the authors reported a photovoltaic efficiency from the sunlight raising about the $7.4 \%$.

Koziol and colleagues (Lekawa-Raus et al., 2017) have shown a few prototypes based on CNT fibers (Figure 8), including a small transformer and a DC generator containing CNT rope windings (substituting copper windings of the primary transformer and of a generator rotor, respectively) (Figures $\mathbf{8 A , B}$ ). The authors found the characteristics of the transformer to be perfectly linear and are not dependent on the material in agreement with the classical theory (Kurzepa et al., 2014) being $10 \mathrm{~mA}$ (p-p) applied 

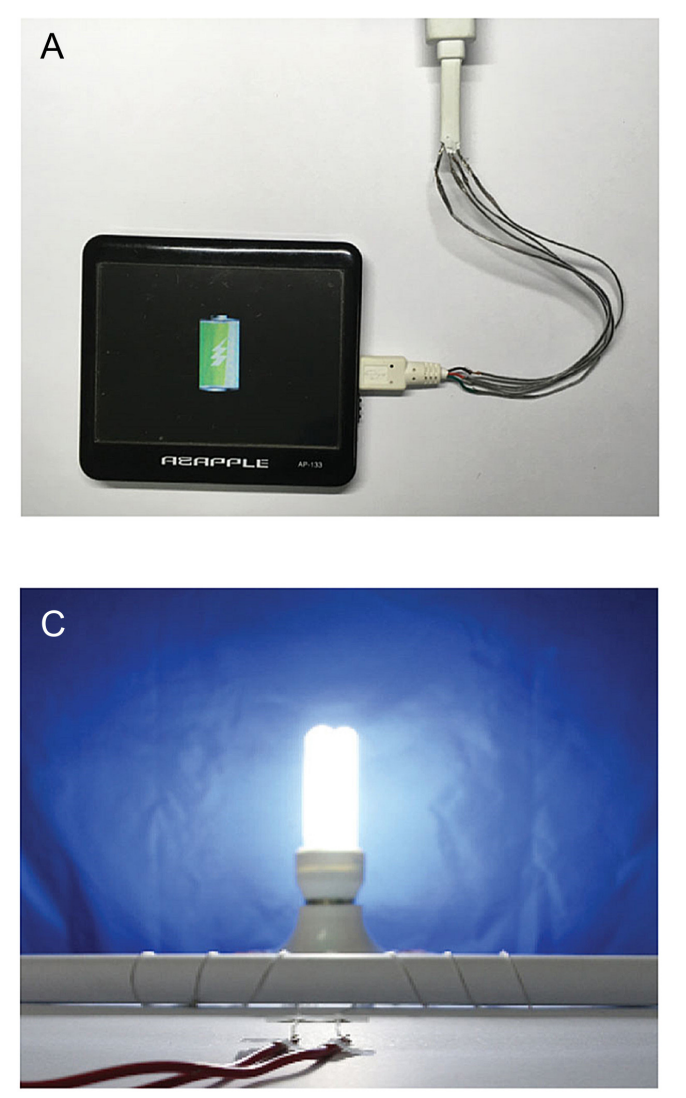
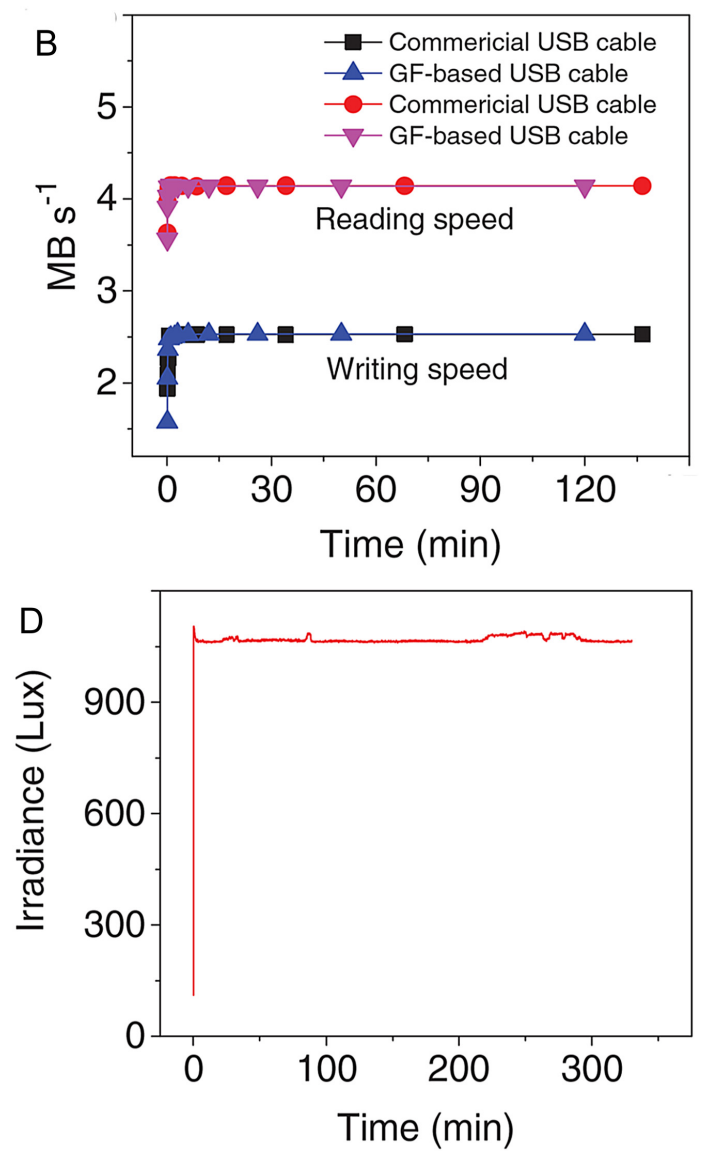

FIGURE 9 | (A) Picture of the USB cable fabricated with graphene fibers. (B) Reading/writing performances of the graphene cable as compared with traditional Cu wires. $(\mathbf{C}, \mathbf{D})$ picture showing a $9 \mathrm{~W}$ working lamp $(220 \mathrm{~V})$ connected with a one meter long Br-doped graphene cable and the irradiance intensity tested along the time. Reproduced from Liu et al. (2016) with permission from Wiley-VCH.

to the primary winding of the transformer in the frequency range of $1-100 \mathrm{kHz}$ (Figure $\mathbf{8 C}$ ). The same authors found also a linear dependence of the maximum generated voltage $(\mathrm{V})$ with the angular velocity (RPM, revolutions per minute) in the 1000$5000 \mathrm{rpm}$ range for a shunt generator based on a CNT fiber (Figures 8D-F). It is however expected that both devices were close to their operational limits, but still limited if compared with the copper-based counterparts. A CNT fiber conductors was fabricated to demonstrate the feasibility as a standard electrical wire (Kurzepa et al., 2014). The home-built cable was successfully tested in sending $10 \mathrm{MB} \mathrm{s}^{-1}$ (Figure 8G). Zhao et al. (2011) reported the fabrication and properties of DWCNT twisted rope, used as a conducting cable loaded with 9 watts, $0.15 \mathrm{~A}, 120 \mathrm{~V}$ of a household bulb (Figures $\mathbf{8 H}-\mathbf{J}$ ) public power.

Liu et al. (2016) reported the preparation of $\mathrm{FeCl}_{3-}, \mathrm{Br}_{2^{-}}$ and K-doped GFs with excellent electrical conductivity by using a two-zone vapor transport method starting from high-purity GFs. Interestingly, the authors fabricated a graphene fiberbased USB cable, which was tested in reading and writing operation speeds as compared with a conventional USB cable (Figures 9A,B). In the same paper, the long-term durability in electrical properties of one-meter long Br-doped graphene cable (60 $\mu \mathrm{m}$ in diameter) connected with a $9 \mathrm{~W}$ lamp (220V) was demonstrated (Figures 9C,D). In the test, a stable irradiance intensity of the lamp was obtained (1060 Lux), which was similar to what obtained by copper wires. The potential uses under practical conditions seems to be limited by the stability of doped graphene (i.e., $\mathrm{K}, \mathrm{FeCl}_{3}, \mathrm{Br}_{2}, \mathrm{I}_{2}$ ) when exposed to air, due to the absorption of oxygen and water (Zhang et al., 2019). For example, a fast modification of the color from yellow to black of the $\mathrm{K}$ - and $\mathrm{FeCl}_{3}$-doped was observed after a few minutes in air, indicating an irreversible modification. In general terms, the instability could be verified by comparing electrical performance of doped graphene fibers with spectroscopic methods (UV-Vis, Raman and XPS techniques), which are very sensitive to the change in the optical, electronic, elemental and structure properties (Liu et al., 2016).

Though the shielding with metal films, composites and fiber mats is much more popular (Zhou et al., 2017; RamírezHerrera et al., 2019), the flexibility and the relatively high electrical conductivity of the assembled fibers make possible shielding characteristics. In fact, by considering the continuously interconnected network realized by the fibers and by the interwoven fibers the application in electromagnetic interference (EMI) shielding is expected, but studies on interference shielding with CNT and graphene yarns are only just beginning and few 

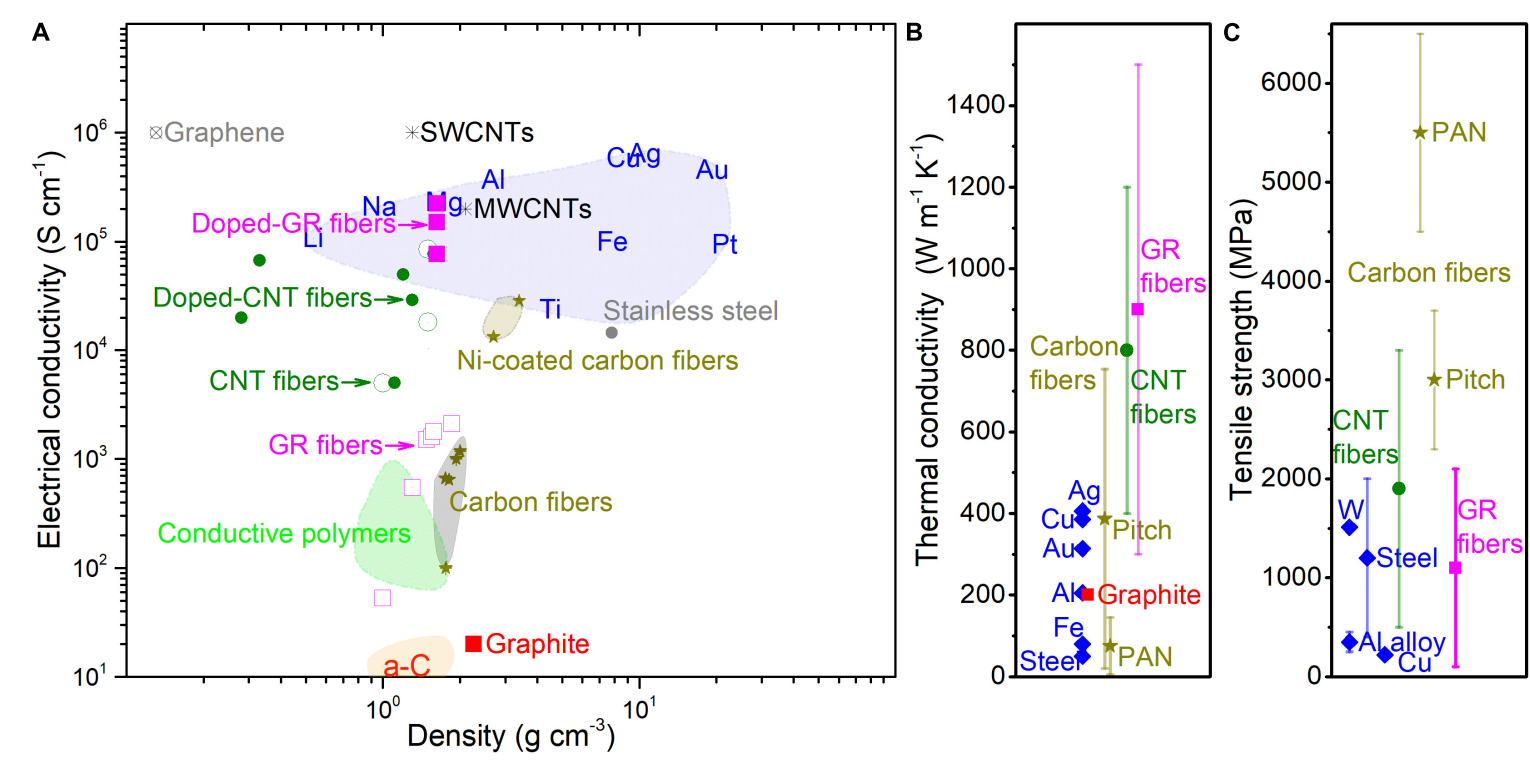

FIGURE 10 | (A) Electrical, (B) thermal conductivities, and (C) tensile strength of CNT- and graphene-fibers (dark green and magenta colors, respectively) as compared to carbon fibers, some metals (brown and blue colors, respectively), and other reference materials.

studies are reported so far. Zeng et al. (2018) fabricated stacked layers with 3D assembled graphene fibers to form thicknesses in the 3.0-26 $\mu \mathrm{m}$ range and measured the EMI shielding properties in the X-band frequency range $(8-12 \mathrm{GHz})$. The authors achieved a record value of shielding effectiveness normalized by density and thickness $\left(\mathrm{SEE}_{/ \mathrm{t}}\right)$ of about $60000 \mathrm{~dB} \mathrm{~cm}^{2} \mathrm{~g}^{-1}$, which is higher than that of conventional materials ( $\mathrm{Cu}$ and $\mathrm{Al}$ foils), of CNT/graphene core-shell foams $\left(51000 \mathrm{~dB} \mathrm{~cm}^{2} \mathrm{~g}^{-1}\right.$ ) (Song et al., 2017) and of $\mathrm{Ti}_{3} \mathrm{C}_{2} \mathrm{~T}_{\mathrm{x}}$ MXene film $\left(\sim 31000 \mathrm{~dB} \mathrm{~cm}^{2}\right.$ $\mathrm{g}^{-1}$ ) (Shahzad et al., 2016). The authors ascribed the high shielding with the porous structure and with the continuously interconnected network that generate an expanded interface and high electrical conductivity. In another recent paper Li et al. (2020) have fabricated a wool-coated CNT coiled yarn fabric with good shielding characteristics and washing durability for wearable E-textile applications.

Electrical/thermal conductivities and tensile strength of the assembled carbon fibers compared to those of other materials (metals, commercial PAN and pitch-derived carbon fibers) are compared (Figures 10A-C). It can be seen from this figure that CNT- and graphene fibers may exhibit properties equivalent or superior to those of metals. However, a wide range of values is observed for the assembled carbon fibers. Such data dispersion is largely determined by several factors. First of all, the basic unit type (SWCNT, MWCNT, graphene) and its main characteristics (aspect ratio, diameter, length, local and structural defect content, purity, presence of impurities and eventually amorphous carbon phases) certainly play a key role, at least at the molecular level. In addition, the structure, morphology and characteristics at the interface between building blocks in forming the fiber scaffold, including chemical bonds, presence of voids and structural defects of the fiber, twisting and wrapping properties are definitely decisive to regulate the fiber properties. Moreover, the doping strategy of CNT and graphene fibers has shown to be crucial for boosting the electrical and thermal properties to record values. However, the stability over time and temperature should be deeply verified and improved to have such fibers as a practical alternative to metals (and commercial carbon fibers). Most importantly, CNTs, graphene and graphene derivatives are becoming cheaper and the ability to control their purity and characteristics, as well as the prospect to assemble the fibers in continuous processes according to industrially viable methods, gives the chance to rapid progress in the field, although it is still difficult to replicate the properties of individual CNT and graphene units to macroscopic fibers.

In conclusion, the carbon-based fiber preparation technology is mature and allows to operate with continuous processes and with industrial equipments, while the fiber doping strategy allows to reach and overcome the electrical/thermal conductivity of metals and with excellent mechanical characteristics. CNTs and graphene are excellent conductors, albeit directionally. At present, they can be used effectively in conductive cables, but not as direct metal replacements. In order to replace traditional cables, there are some issues that need to be deeply investigated, such as stability over time and temperature (in the case of doping). Two final aspects deserve to be mentioned. First of all, the electrical cable insulation, which appears to be relatively simple (Lekawa-Raus et al., 2014a) with polymer coating the carbon cable. Moreover, the connection of CNT and graphene fibers with traditional cables is more difficult and represent a non-secondary standpoint to be solved. In the laboratory practice electrodes and electrical connections are made with $\mathrm{Au}$ film, silver, other metals (e.g. In), alloys or carbon paste, but who tried to build interconnections with traditional electronics realized the difficulty of the conventional 
joints (i.e., soldering, crimping, etc.), which have no durability and are quite inappropriate to the pure carbon assemblies. The topic has not received so far all the attention it deserves and very few studies have been targeted at this issue (Burda et al., 2015; Ebrahimian and Kokabi, 2017; Kim et al., 2018; Milowska et al., 2019; Fu et al., 2020).

\section{SUMMARY AND OUTLOOK}

The review summarizes the scientific progress in the field of carbon-based fibers to be used as electrical conductors, from the origin to the most recent findings. From graphite and first developed pyrolyzed fibers to carbon fibers and assembled nanocarbons (carbon nanotubes and graphene sheets) into fibers/yarns/ropes the issue has been progressively renewed to translate the carbon attributes into materials at the frontier. The main addressed theme is about the most recent innovations concerning the doping paradigm of all-carbon fibers/based on carbon nanotubes and/or graphene, emphasizing the role played by the chemistry. Taking advantage of the doping with metal and with non-metal compounds unprecedented electrical properties are observed achieving the metal counterpart values. Along this line, the conductivity record values have been found much higher than those of metals, thus demonstrating the potential to substitute them in some prototypes reported in the recent literature. Moreover, the other advantages provided by allcarbon fibers over conventional metals are manifold, including

\section{REFERENCES}

Aboutalebi, S. H., Jalili, R., Esrafilzadeh, D., Salari, M., Gholamvand, Z., Aminorroaya Yamini, S., et al. (2014). High-performance multifunctional graphene yarns: toward wearable all-carbon energy storage textiles. ACS Nano 8, 2456-2466. doi: 10.1021/nn406026z

Afroj, S., Karim, N., Wang, Z., Tan, S., He, P., Holwill, M., et al. (2019). Engineering graphene flakes for wearable textile sensors via highly scalable and ultrafast yarn dyeing technique. ACS Nano 13, 3847-3857. doi: 10.1021/acsnano.9b00319

Ajayan, P. M. (1999). Nanotubes from carbon. Chem. Rev. 99, 1787-1800. doi: $10.1021 / \mathrm{cr} 970102 \mathrm{~g}$

Alemán, B., Reguero, V., Mas, B., and Vilatela, J. J. (2015). Strong carbon nanotube fibers by drawing inspiration from polymer fiber spinning. ACS Nano 9, 7392-7398. doi: 10.1021/acsnano.5b02408

Anthony, D. B., Sui, X. M., Kellersztein, I., De Luca, H. G., White, E. R., Wagner, H. D., et al. (2018). Continuous carbon nanotube synthesis on charged carbon fibers. Comp. Part A Appl. Sci. Manufact. 112, 525-538.

Bacon, R. (1959). Growth, structure, and properties of graphite whiskers. J. Appl. Phys. 31, 283-290. doi: 10.1063/1.1735559

Barnett, C. J., Evans, C., Mccormack, J. E., Gowenlock, C. E., Dunstan, P., Adams, W., et al. (2019). Experimental measurement of angular and overlap dependence of conduction between carbon nanotubes of identical chirality and diameter. Nano Lett. 19, 4861-4865. doi: 10.1021/acs.nanolett.9b00025

Behabtu, N., Young, C. C., Tsentalovich, D. E., Kleinerman, O., Wang, X., Ma, A. W. K., et al. (2013). Strong, light, multifunctional fibers of carbon nanotubes with ultrahigh conductivity. Science 339, 182-186. doi: 10.1126/ science. 1228061

Burda, M., Lekawa-Raus, A., Gruszczyk, A., and Koziol, K. K. K. (2015). Soldering of carbon materials using transition metal rich alloys. ACS Nano 9, 8099-8107. doi: 10.1021 /acsnano.5b02176

Cai, W., Lai, T., and Ye, J. (2015). A spinneret as the key component for surfaceporous graphene fibers in high energy density micro-supercapacitors. J. Mater. Chem. A 3, 5060-5066. doi: 10.1039/C5TA00365B low weight, environmental and chemical stability, flexibility and mechanical properties. Despite the great advancement in the field, some problems should be addressed, including longterm stability, high-performance electrical properties, scalable and cost-effective production methods and interconnection with traditional cables. CNTs and graphene are excellent conductors, albeit directionally. At present, they can be used effectively in conductive cables, but not as direct metal replacements. We can expect a great development in the next years in particular in the flexible and wearable electronics, such as multifunctional fabrics, power cables, energy harvesting and storage and sensing device fields.

\section{AUTHOR CONTRIBUTIONS}

FC wrote and organized the manuscript. MU, KL, MZ, and DS provided a substantial contribution to the work. All authors approved it for publication.

\section{FUNDING}

This work was supported by MIUR (Ministero dell'Istruzione, dell'Università e della Ricerca), INSTM Consorzio and NIS (Nanostructured Interfaces and Surfaces) Inter-Departmental Centre of University of Turin.
Cecone, C., Caldera, F., Anceschi, A., Scalarone, D., Trotta, F., Bracco, P., et al. (2018). One-step facile process to obtain insoluble polysaccharides fibrous mats from electrospinning of water-soluble PMDA/cyclodextrin polymer. J. Appl. Polym. Sci. 135:46490. doi: 10.1002/app.46490

Cesano, F., Bertarione, S., Scarano, D., and Zecchina, A. (2005). Connecting carbon fibers by means of catalytically grown nanofilaments: formation of carboncarbon composites. Chem. Mater. 17, 5119-5123. doi: 10.1021/cm050427a

Cesano, F., Rattalino, I., Bardelli, F., Sanginario, A., Gianturco, A., Veca, A., et al. (2013). Structure and properties of metal-free conductive tracks on polyethylene/multiwalled carbon nanotube composites as obtained by laser stimulated percolation. Carbon 61, 63-71. doi: 10.1016/j.carbon.2013.04.066

Cesano, F., and Scarano, D. (2015). "Dispersion of carbon-based materials (CNTs, Graphene) in polymer matrices," in Carbon for Sensing Devices, eds D. Demarchi and A. Tagliaferro (Heidelberg: Springer International Publishing), 43-75. doi: 10.1007/978-3-319-08648-4_3

Cesano, F., and Scarano, D. (2018). Graphene and other 2D layered hybrid nanomaterial-based films: synthesis, properties, and applications. Coatings 8:419. doi: 10.3390/coatings8120419

Cesano, F., Zaccone, M., Armentano, I., Cravanzola, S., Muscuso, L., Torre, L., et al. (2016). Relationship between morphology and electrical properties in PP/MWCNT composites: processing-induced anisotropic percolation threshold. Mater. Chem. Phys. 180, 284-290. doi: 10.1016/j.matchemphys.2016. 06.009

Cheng, J., and Lee, S.-H. (2016). Development of new smart materials and spinning systems inspired by natural silks and their applications. Front. Mater. 2:74. doi: $10.3389 /$ fmats.2015.00074

Chong, W. G., Xiao, F., Yao, S., Cui, J., Sadighi, Z., Wu, J., et al. (2019). Nitrogendoped graphene fiber webs for multi-battery energy storage. Nanoscale 11, 6334-6342. doi: 10.1039/C8NR10025J

Chou, T. W., Gao, L., Thostenson, E. T., Zhang, Z., and Byun, J. H. (2010). An assessment of the science and technology of carbon nanotube-based fibers and composites. Comp. Sci. Technol. 70, 1-19. doi: 10.1016/j.compscitech.2009.10. 004 
Chowdhury, A. R., Jaksik, J., Hussain, I., Longoria, R., Faruque, O., Cesano, F., et al. (2019). Multicomponent nanostructured materials and interfaces for efficient piezoelectricity. Nano-Struct. Nano-Objects 17, 148-184. doi: 10.1016/j.nanoso. 2018.12.002

Chung, D. D. L. (2017). "1 - Carbon fibers, nanofibers, and nanotubes," in Carbon Composites, 2nd Edn, ed. D. D. L. Chung (Oxford: Butterworth-Heinemann), 1-87. doi: 10.1016/b978-0-12-804459-9.00001-4

Clancy, A. J., Bayazit, M. K., Hodge, S. A., Skipper, N. T., Howard, C. A., and Shaffer, M. S. P. (2018). Charged carbon nanomaterials: redox chemistries of fullerenes, carbon nanotubes, and graphenes. Chem. Rev. 118, 7363-7408. doi: 10.1021/acs.chemrev.8b00128

Cong, H. P., Chen, J. F., and Yu, S. H. (2014). Graphene-based macroscopic assemblies and architectures: an emerging material system. Chem Soc. Rev. 43, 7295-7325. doi: 10.1039/c4cs00181h

Cravanzola, S., Haznedar, G., Scarano, D., Zecchina, A., and Cesano, F. (2013). Carbon-based piezoresistive polymer composites: structure and electrical properties. Carbon 62, 270-277. doi: 10.1016/j.carbon.2013.05.064

Cravotto, G., Garella, D., Calcio Gaudino, E., Turci, F., Bertarione, S., Agostini, G., et al. (2011). Rapid purification/oxidation of multi-walled carbon nanotubes under $300 \mathrm{kHz}$-ultrasound and microwave irradiation. New J. Chem. 35, 915919. doi: 10.1039/c0nj00892c

De Jong, K. P., and Geus, J. W. (2000). Carbon nanofibers: catalytic synthesis and applications. Cat. Rev. Sci. Engin. 42, 481-510. doi: 10.1081/CR-100101954

Derbyshire, F. J., Presland, A. E. B., and Trimm, D. L. (1975). Graphite formation by the dissolution-precipitation of carbon in cobalt, nickel and iron. Carbon 13, 111-113. doi: 10.1016/0008-6223(75)90267-5

Dhanabalan, S. C., Dhanabalan, B., Chen, X., Ponraj, J. S., and Zhang, H. (2019). Hybrid carbon nanostructured fibers: stepping stone for intelligent textilebased electronics. Nanoscale 11, 3046-3101. doi: 10.1039/C8NR07554A

Dini, Y., Faure-Vincent, J., and Dijon, J. (2019). How to overcome the electrical conductivity limitation of carbon nanotube yarns drawn from carbon nanotube arrays. Carbon 144, 301-311. doi: 10.1016/j.carbon.2018.12.041

Dini, Y., Rouchon, D., Faure-Vincent, J., and Dijon, J. (2020). Large improvement of CNT yarn electrical conductivity by varying chemical doping and annealing treatment. Carbon 156, 38-48. doi: 10.1016/j.carbon.2019.09.022

Dresselhaus, M. S., and Dresselhaus, G. (2002). Intercalation compounds of graphite. Adv. Phys. 51, 1-186. doi: 10.1080/00018730110113644

Dresselhaus, M. S., Jorio, A., Hofmann, M., Dresselhaus, G., and Saito, R. (2010). Perspectives on carbon nanotubes and graphene Raman spectroscopy. Nano Lett. 10, 751-758. doi: 10.1021/nl904286r

Ebrahimian, A., and Kokabi, A. H. (2017). Friction stir soldering: a novel route to produce graphite-copper dissimilar joints. Mater. Des. 116, 599-608. doi: 10.1016/j.matdes.2016.12.057

Eckmann, A., Felten, A., Mishchenko, A., Britnell, L., Krupke, R., Novoselov, K. S., et al. (2012). Probing the nature of defects in graphene by Raman spectroscopy. Nano Lett. 12, 3925-3930. doi: 10.1021/nl300901a

Ericson, L. M., Fan, H., Peng, H., Davis, V. A., Zhou, W., Sulpizio, J., et al. (2004). Macroscopic, neat, single-walled carbon nanotube fibers. Science 305, 1447-1450. doi: 10.1126/science. 1101398

Fan, T., Zhao, C., Xiao, Z., Guo, F., Cai, K., Lin, H., et al. (2016). Fabricating of highperformance functional graphene fibers for micro-capacitive energy storage. Sci. Rep. 6:29534. doi: 10.1038/srep29534

Fang, B., Chang, D., Xu, Z., and Gao, C. (2020). Review on graphene fibers: expectations, advances, and prospects. Adv. Mater. 32:1902664. doi: 10.1002/ adma.201902664

Fischer, J. E. (2006). “Ch 2: Carbon nanotubes: structure and properties," in Carbon Nanomaterials ed Y. Gogotsi (Boca Raton, FL: Taylor \& Francis).

Fischer, J. E., and Thompson, T. E. (1978). Graphite intercalation compounds. Phys. Today 31, 36-45. doi: 10.1063/1.2995104

Foroughi, J., and Spinks, G. (2019). Carbon nanotube and graphene fiber artificial muscles. Nanoscale Adv. 1, 4592-4614. doi: 10.1039/C9NA00038K

Fu, H., Xiao, Y., Song, R., Wang, Z., Ji, H., and He, D. (2020). Rapid soldering of flexible graphene assembled films at low temperature in air with ultrasonic assistance. Carbon 158, 55-62. doi: 10.1016/j.carbon.2019.11.089

Fujita, S., and Suzuki, A. (2010). Theory of temperature dependence of the conductivity in carbon nanotubes. J. Appl. Phys. 107:013711. doi: 10.1063/1. 3280035
García-Mateos, F. J., Ruiz-Rosas, R., Rosas, J. M., Rodríguez-Mirasol, J., and Cordero, T. (2019). Controlling the composition, morphology, porosity, and surface chemistry of lignin-based electrospun carbon materials. Front. Mater. 6:114. doi: 10.3389/fmats.2019.00114

Groppo, E., Bonino, F., Cesano, F., Damin, A., and Manzoli, M. (2018). "Raman, IR and INS characterization of functionalized carbon materials," in Metal-free Functionalized Carbons in Catalysis: Synthesis, Characterization and Applications, eds A. Villa and N. Dimitratos (London: Royal Society of Chemistry), 103-137. doi: 10.1039/9781788013116-00103

Hada, M., Hasegawa, T., Inoue, H., Takagi, M., Omoto, K., Chujo, D., et al. (2019). One-minute Joule annealing enhances the thermoelectric properties of carbon nanotube yarns via the formation of graphene at the interface. ACS Appl. Ener. Mater. 2, 7700-7708. doi: 10.1021/acsaem.9b01736

Harun, S. W., Stauber, T., Ozkan, C., Celasco, E., Chaika, A. N., Zhang, M., et al. (eds) (2019). Handbook of Graphene, Vol. 1-8. Hoboken, NJ: Wiley.

Haznedar, G., Cravanzola, S., Zanetti, M., Scarano, D., Zecchina, A., and Cesano, F. (2013). Graphite nanoplatelets and carbon nanotubes based polyethylene composites: electrical conductivity and morphology. Mater. Chem. Phys. 143, 47-52. doi: 10.1016/j.matchemphys.2013.08.008

Headrick, R. J., Tsentalovich, D. E., Berdegué, J., Bengio, E. A., Liberman, L., Kleinerman, O., et al. (2018). Structure-property relations in carbon nanotube fibers by downscaling solution processing. Adv. Mater. 30:1704482. doi: 10 . 1002/adma.201704482

Hennig, G. (1952). The properties of the interstitial compounds of graphite. III. The electrical properties of the halogen compounds of graphite. J. Chem. Phys. 20, 1443-1447. doi: 10.1063/1.1700778

Hills, G., Lau, C., Wright, A., Fuller, S., Bishop, M. D., Srimani, T., et al. (2019). Modern microprocessor built from complementary carbon nanotube transistors. Nature 572, 595-602. doi: 10.1038/s41586-019-1493-8

Hong, S., and Myung, S. (2007). A flexible approach to mobility. Nat. Nanotechnol. 2, 207-208. doi: 10.1038/nnano.2007.89

Iijima, S., Ajayan, P. M., and Ichihashi, T. (1992). Growth model for carbon nanotubes. PRL 69, 3100-3103. doi: 10.1103/PhysRevLett.69.3100

Iijima, S., and Ichihashi, T. (1993). Single-shell carbon nanotubes of 1-nm diameter. Nature 363, 603-605. doi: 10.1038/363603a0

Jain, S. M., Cesano, F., Scarano, D., and Edvinsson, T. (2017). Resonance raman and IR spectroscopy of aligned carbon nanotube arrays with extremely narrow diameters prepared with molecular catalysts on steel substrates. PCCP 19, 30667-30674. doi: 10.1039/C7CP06973A

Jakubinek, M. B., Johnson, M. B., White, M. A., Jayasinghe, C., Li, G., Cho, W., et al. (2012). Thermal and electrical conductivity of array-spun multi-walled carbon nanotube yarns. Carbon 50, 244-248. doi: 10.1016/j.carbon.2011.08.041

Jang, Y., Kim, S. M., Spinks, G. M., and Kim, S. J. (2019). Carbon nanotube yarn for fiber-shaped electrical sensors, actuators, and energy storage for smart systems. Adv. Mater. 32:1902670. doi: 10.1002/adma.201902670

Jiang, K., Li, Q., and Fan, S. (2002). Spinning continuous carbon nanotube yarns. Nature 419:801. doi: 10.1038/419801a

Karakassides, A., Ganguly, A., Tsirka, K., Paipetis, A. S., and Papakonstantinou, P. (2020). Radially grown graphene nanoflakes on carbon fibers as reinforcing interface for polymer composites. ACS Appl. Nano Mater. 3, 2402-2413. doi: 10.1021/acsanm.9b02536

Kharlamova, M. V. (2017). Investigation of growth dynamics of carbon nanotubes. Beilstein J. Nanotechnol. 8, 826-856. doi: 10.3762/bjnano.8.85

Kim, S. H., Choi, J.-P., Eom, Y.-S., Nam, Y., Baek, S., and Aranas, C. (2018). A phenomenological study of a $\mathrm{Sn}-\mathrm{Ag}-\mathrm{Al}$ composite solder reinforced with $\mathrm{Mg}-$ MWCNT: improved electrical conductivity and thermo-physical performance. Mater. Des. 140, 196-208. doi: 10.1016/j.matdes.2017.11.073

Kim, S. H., Haines, C. S., Li, N., Kim, K. J., Mun, T. J., Choi, C., et al. (2017). Harvesting electrical energy from carbon nanotube yarn twist. Science 357, 773-778. doi: 10.1126/science.aam8771

Kou, L., Huang, T., Zheng, B., Han, Y., Zhao, X., Gopalsamy, K., et al. (2014). Coaxial wet-spun yarn supercapacitors for high-energy density and safe wearable electronics. Nat. Commun. 5:3754. doi: 10.1038/ncomms4754

Kou, L., Liu, Y., Zhang, C., Shao, L., Tian, Z., Deng, Z., et al. (2017). A mini review on nanocarbon-based 1D macroscopic fibers: assembly strategies and mechanical properties. Nano-Micro Lett. 9:51. doi: 10.1007/s40820-0170151-7 
Kumar, M., Gowda, A., and Kumar, S. (2017). Discotic liquid crystals with graphene: supramolecular self-assembly to applications. Part. Part. Syst. Charact. 34:1700003. doi: 10.1002/ppsc.201700003

Kurzepa, L., Lekawa-Raus, A., Patmore, J., and Koziol, K. (2014). Replacing Copper wires with carbon nanotube wires in electrical transformers. Adv. Func. Mater. 24, 619-624. doi: 10.1002/adfm.201302497

Lee, C. H., Liu, W.-W., Chai, S.-P., Mohamed, A. R., Aziz, A., Khe, C.-S., et al. (2017). Review of the synthesis, transfer, characterization and growth mechanisms of single and multilayer graphene. Adv. Mater. 7, 15644-15693. doi: 10.1039/C7RA00392G

Lee, J., Lee, D.-M., Jung, Y., Park, J., Lee, H. S., Kim, Y.-K., et al. (2019a). Direct spinning and densification method for high-performance carbon nanotube fibers. Nat. Commun. 10:2962. doi: 10.1038/s41467-019-10998-0

Lee, T., Park, K. T., Ku, B. C., and Kim, H. (2019b). Carbon nanotube fibers with enhanced longitudinal carrier mobility for high-performance allcarbon thermoelectric generators. Nanoscale 11, 16919-16927. doi: 10.1039/ C9NR05757A

Lekawa-Raus, A., Gizewski, T., Patmored, J., Kurzepa, L., and Koziol, K. K. (2017). Electrical transport in carbon nanotube fibres. Scripta Mater. 131, 112-118. doi: 10.1016/j.scriptamat.2016.11.027

Lekawa-Raus, A., Kurzepa, L., Peng, X., and Koziol, K. (2014a). Towards the development of carbon nanotube based wires. Carbon 68, 597-609. doi: 10. 1016/j.carbon.2013.11.039

Lekawa-Raus, A., Patmore, J., Kurzepa, L., Bulmer, J., and Koziol, K. (2014b). Electrical properties of carbon nanotube based fibers and their future use in electrical wiring. Adv. Funct. Mater. 24, 3661-3682. doi: 10.1002/adfm. 201303716

Lepak-Kuc, S., Boncel, S., Szybowicz, M., Nowicka, A. B., Jozwik, I., Orlinski, K., et al. (2018). The operational window of carbon nanotube electrical wires treated with strong acids and oxidants. Sci. Rep. 8:14332. doi: 10.1038/s41598018-32663-0

Lepak-Kuc, S., Milowska, K. Z., Boncel, S., Szybowicz, M., Dychalska, A., Jozwik, I., et al. (2019). Highly conductive doped hybrid carbon nanotube-graphene wires. ACS Appl. Mater. Interf. 11, 33207-33220. doi: 10.1021/acsami.9b08198

Li, J., and Pandey, G. P. (2015). Advanced physical chemistry of carbon nanotubes. Ann. Rev. Phys. Chem. 66, 331-356. doi: 10.1146/annurev-physchem-040214121535

Li, Q., Li, Y., Zhang, X., Chikkannanavar, S. B., Zhao, Y., Dangelewicz, A. M., et al. (2007). Structure-dependent electrical properties of carbon nanotube fibers. Adv. Mater. 19:3358. doi: 10.1002/adma.200602966

Li, W., Xu, C., Ren, X., Xue, Y., Zhao, J., Li, Q., et al. (2020). Anti-fatigue and multifunctional core-spun yarns based on carbon nanotube springs. Comp. Commun. 19, 127-133. doi: 10.1016/j.coco.2020.03.008

Li, X., Cai, W., An, J., Kim, S., Nah, J., Yang, D., et al. (2009). Large-area synthesis of high-quality and uniform graphene films on copper foils. Science 324, 1312-1314. doi: 10.1126/science.1171245

Li, Y. L., Kinloch, I. A., and Windle, A. H. (2004). Direct spinning of carbon nanotube fibers from chemical vapor deposition synthesis. Science 304, 276278. doi: $10.1126 /$ science. 1094982

Li, Z., Liu, Z., Sun, H., and Gao, C. (2015). Superstructured assembly of nanocarbons: fullerenes, nanotubes, and graphene. Chem. Rev. 115, 7046-1117. doi: 10.1021/acs.chemrev.5b00102

Liu, K., Zhu, F., Liu, L., Sun, Y., Fan, S., and Jian, K. (2012). Fabrication and processing of high-strength densely packed carbon nanotubeyarns without solution processes. Nanoscale 4, 3389-3393. doi: 10.1039/c2nr30 $226 \mathrm{~h}$

Liu, Q., Zhou, J., Song, C., Li, X., Wang, Z., Yang, J., et al. (2020a). 2.2V high performance symmetrical fiber-shaped aqueous supercapacitors enabled by "water-in-salt" gel electrolyte and N-Doped graphene fiber. En. Stor. Mater. 24, 495-503. doi: 10.1016/j.ensm.2019.07.008

Liu, Y., Yang, M., Pang, K., Wang, F., Xu, Z., Gao, W., et al. (2020b). Environmentally stable macroscopic graphene films with specific electrical conductivity exceeding metals. Carbon 156, 205-211. doi: 10.1016/j.carbon. 2019.09.066

Liu, Y., Liang, H., Xu, Z., Xi, J., Chen, G., Gao, W., et al. (2017). Superconducting continuous graphene fibers via calcium intercalation. ACS Nano 11, 4301-4306. doi: 10.1021/acsnano.7b01491
Liu, Y., Xu, Z., Zhan, J., Li, P., and Gao, C. (2016). Superb electrically conductive graphene fibers via doping strategy. Adv. Mater. 28, 7941-7947. doi: 10.1002/ adma.201602444

Lu, W., Zu, M., Byun, J. H., Kim, B. S., and Chou, T. W. (2012). State of the art of carbon nanotube fibers: opportunities and challenges. Adv. Mater. 24, 1805-1833. doi: 10.1002/adma.201104672

Lu, Z., Foroughi, J., Wang, C., Long, H., and Wallace, G. G. (2017). Superelastic hybrid CNT/graphene fibers for wearable energy storage. Adv. Ener. Mater. 8:1702047. doi: $10.1002 /$ aenm.201702047

Lu, Z., Raad, R., Safaei, F., Xi, J., Liu, Z., and Foroughi, J. (2019). Carbon nanotube based fiber supercapacitor as wearable energy storage. Front. Mater. 6:138. doi: $10.3389 /$ fmats.2019.00138

Ma, T., Gao, H.-L., Cong, H.-P., Yao, H.-B., Wu, L., Yu, Z.-Y., et al. (2018). A bioinspired interface design for improving the strength and electrical conductivity of graphene-based fibers. Adv. Mater. 30:1706435. doi: 10.1002/ adma. 201706435

Mäder, E., Liu, J., Hiller, J., Lu, W., Li, Q., Zhandarov, S., et al. (2015). Coating of carbon nanotube fibers: variation of tensile properties, failure behavior, and adhesion strength. Front. Mater. 2:53. doi: 10.3389/fmats.2015.00053

Meunier, V., Senet, P., and Lambin, P. (1999). Scanning tunneling spectroscopy signature of finite-size and connected nanotubes: a tight-binding study. Phys. Rev. B 60:7792. doi: 10.1103/PhysRevB.60.7792

Miao, M. (2011). Electrical conductivity of pure carbon nanotube yarns. Carbon 49, 3755-3761. doi: 10.1016/j.carbon.2011.05.008

Miao, M. (2013). Yarn spun from carbon nanotube forests: production, structure, properties and applications. Particuology 11, 378-393. doi: 10.1016/j.partic. 2012.06.017

Milowska, K. Z., Burda, M., Wolanicka, L., Bristowe, P. D., and Koziol, K. K. K. (2019). Carbon nanotube functionalization as a route to enhancing the electrical and mechanical properties of $\mathrm{Cu}-\mathrm{CNT}$ composites. Nanoscale 11, 145-157. doi: $10.1039 /$ C8NR07521B

Mirfakhrai, T., Kozlov, M., Fang, S., Zhang, M., Baughman, R. H., and Madden, J. D. (2008). "Carbon nanotube yarns: sensors, actuators and current carriers," in Proceedings of SPIE - The International Society for Optical Engineering, Texas, TX.

Mohammadzadehmoghadam, S., and Dong, Y. (2019). Fabrication and characterization of electrospun silk fibroin/gelatin scaffolds crosslinked with glutaraldehyde vapor. Front. Mater. 6:91. doi: 10.3389/fmats.2019.00091

Newcomb, B. A., and Chae, H. G. (2018). "Ch 21: The properties of carbon fibers," in Handbook of Properties of Textile and Technical Fibres, 2nd Edn, ed. A. R. Bunsell (Cambridge: Woodhead Publishing).

Ottmers, D. M., and Rase, H. F. (1966). Potassium graphites prepared by mixedreaction technique. Carbon 4, 125-127. doi: 10.1016/0008-6223(66)90017-0

Panwar, N., Soehartono, A. M., Chan, K. K., Zeng, S., Xu, G., Qu, J., et al. (2019). Nanocarbons for biology and medicine: sensing, imaging, and drug delivery. Chem. Rev. 119, 9559-9656. doi: 10.1021/acs.chemrev.9b0 0099

Papageorgiou, D. G., Kinloch, I. A., and Young, R. J. (2017). Mechanical properties of graphene and graphene-based nanocomposites. Progr. Mat. Sci. 90, 75-127. doi: 10.1016/j.pmatsci.2017.07.004

Park, H., Ambade, R. B., Noh, S. H., Eom, W., Koh, K. H., Ambade, S. B., et al. (2019a). Porous graphene-carbon nanotube scaffolds for fiber supercapacitors. ACS Appl. Mater. Interf. 11, 9011-9022. doi: 10.1021/acsami.8b1 7908

Park, Y., Hembram, K. P. S. S., Yoo, R., Jang, B., Lee, W., Lee, S. G., et al. (2019b). Reinterpretation of single-wall carbon nanotubes by Raman spectroscopy. J. Phys. Chem. C 123, 14003-14009. doi: 10.1021/acs.jpcc.9b02174

Peng, L., Xu, Z., Liu, Z., Guo, Y., Li, P., and Gao, C. (2017). Ultrahigh thermal conductive yet superflexible graphene films. Adv. Mater. 29:1700589. doi: 10. 1002/adma.201700589

Powell, R. L., and Childs, G. E. (1972). American Institute of Physics Handbook, 3rd Edn. New York, NY: McGraw-Hill, 4-160.

Ramírez-Herrera, C. A., Gonzalez, H., De La Torre, F., Benitez, L., CabañasMoreno, J. G., and Lozano, K. (2019). Electrical properties and electromagnetic interference shielding effectiveness of interlayered systems composed by carbon nanotube filled carbon nanofiber mats and polymer composites. Nanomaterials 9:238. doi: 10.3390/nano9020238 
Randeniya, L. K., Bendavid, A., Martin, P. J., and Tran, C. D. (2010). Composite yarns of multiwalled carbon nanotubes with metallic electrical conductivity. Small 6, 1806-1811. doi: 10.1002/smll.201000493

Reina, A., Jia, X., Ho, J., Nezich, D., Son, H., Bulovic, V., et al. (2009). Large area, few-layer graphene films on arbitrary substrates by chemical vapor deposition. Nano Lett. 9, 30-35. doi: 10.1021/nl801827v

Rodriguez, N. M., Chambers, A., and Baker, R. T. K. (1995). Catalytic engineering of carbon nanostructures. Langmuir 11, 3862-3866. doi: 10.1021/la00010a042

Ross, R. B. (1992). Metallic Materials Specification Handbook, 4th Edn. London: Chapman \& Hall.

Ryu, S., Chou, J. B., Lee, K., Lee, D., Hong, S. H., Zhao, R., et al. (2015). Direct insulation-to-conduction transformation of adhesive catecholamine for simultaneous increases of electrical conductivity and mechanical strength of CNT fibers. Adv. Mater. 27, 3250-3255. doi: 10.1002/adma.201500914

Saito, R., Hofmann, M., Dresselhaus, G., Jorio, A., and Dresselhaus, M. S. (2011). Raman spectroscopy of graphene and carbon nanotubes. Adv. Phys. 60, 413550. doi: 10.1080/00018732.2011.582251

Salavagione, H. J., Gómez-Fatou, M. A., Shuttleworth, P. S., and Ellis, G. J. (2018). New perspectives on graphene/polymer fibers and fabrics for smart textiles: the relevance of the polymer/graphene interphase. Front. Mater. 5:18. doi: 10.3389/ fmats.2018.00018

Sears, K., Skourtis, C., Atkinson, K., Finn, N., and Humphries, W. (2010). Focused ion beam milling of carbon nanotube yarns to study the relationship between structure and strength. Carbon 48, 4450-4456. doi: 10.1016/j.carbon.2010. 08.004

Shahzad, F., Alhabeb, M., Hatter, C. B., Anasori, B., Man Hong, S., Koo, C. M., et al. (2016). Electromagnetic interference shielding with 2D transition metal carbides (MXenes). Science 353:1137. doi: 10.1126/science.aag 2421

Song, Q., Ye, F., Yin, X., Li, W., Li, H., Liu, Y., et al. (2017). Carbon nanotubemultilayered graphene edge plane core-shell hybrid foams for ultrahighperformance electromagnetic-interference shielding. Adv. Mater. 29:1701583. doi: 10.1002/adma.201701583

Sun, H., Fu, C., Gao, Y., Guo, P., Wang, C., Yang, W., et al. (2018). Electrical property of macroscopic graphene composite fibers prepared by chemical vapor deposition. Nanotechnol. 29:305601. doi: 10.1088/1361-6528/aac260

Sundaram, R. M., Koziol, K. K. K., and Windle, A. H. (2011). Continuous direct spinning of fibers of single-walled carbon nanotubes with metallic chirality. Adv. Mater. 23, 5064-5068. doi: 10.1002/adma.201102754

Thess, A., Lee, R., Nikolaev, P., Dai, H., Petit, P., Robert, J., et al. (1996). Crystalline ropes of metallic carbon nanotubes. Science 273, 483-487. doi: 10.1126/science. 273.5274 .483

Tibbetts, G. G. (1985). Lengths of carbon filaments grown from iron catalyst particles in natural gas. J. Cryst. Growth 73, 431-438. doi: 10.1016/00220248(85)90005-3

Tsentalovich, D. E., Headrick, R. J., Mirri, F., Hao, J., Behabtu, N., Young, C. C., et al. (2017). Influence of carbon nanotube characteristics on macroscopic fiber properties. ACS Appl. Mater. Interf. 9, 36189-36198. doi: 10.1021/acsami. $7 \mathrm{~b} 10968$

Tsukamoto, J., Matsumura, K., Takahashi, T., and Sakoda, K. (1986). Structure and conductivity of graphite fibres prepared by pyrolysis of cyanoacetylene. Synth. Metals 13, 255-264. doi: 10.1016/0379-6779(86)90075-5

Uddin, M. J., Daramola, D. E., Velasquez, E., Dickens, T. J., Yan, J., Hammel, E., et al. (2014). A high efficiency 3D photovoltaic microwire with carbon nanotubes (CNT)-quantum dot (QD) hybrid interface. Phys. Status Solidi. RRL 8, 898-903. doi: 10.1002/pssr.201409392

Veedu, V. P., Cao, A. Y., Li, X. S., Ma, K. G., Soldano, C., Kar, S., et al. (2006). Multifunctional composites using reinforced laminae with carbon-nanotube forests. Nat. Mater. 5, 457-462. doi: 10.1038/nmat1650

Vishwakarma, R., Zhu, R., Abuelwafa, A. A., Mabuchi, Y., Adhikari, S., Ichimura, S., et al. (2019). Direct synthesis of large-area graphene on insulating substrates at low temperature using microwave plasma CVD. ACS Omega 4, 11263-11270. doi: 10.1021/acsomega.9b00988

Wang, G., Kim, S. K., Wang, M. C., Zhai, T., Munukutla, S., Girolami, G. S., et al. (2020). Enhanced electrical and mechanical properties of chemically cross-linked carbon-nanotube-based fibers and their application in highperformance supercapacitors. ACS Nano 14, 632-639. doi: 10.1021/acsnano.9 b07244
Wang, J. N., Luo, X. G., Wu, T., and Chen, Y. (2014). High-strength carbon nanotube fibre-like ribbon with high ductility and high electrical conductivity. Nat. Commun. 5:3848. doi: 10.1038/ncomms4848

Wang, K., Frewin, C. L., Esrafilzadeh, D., Yu, C., Wang, C., Pancrazio, J. J., et al. (2019). High-performance graphene-fiber-based neural recording microelectrodes. Adv. Mater. 31:1805867. doi: 10.1002/adma.201805867

Xin, G., Zhu, W., Deng, Y., Cheng, J., Zhang, L. T., Chung, A. J., et al. (2019). Microfluidics-enabled orientation and microstructure control of macroscopic graphene fibres. Nat. Nanotechnol. 14, 168-175. doi: 10.1038/s41565-0180330-9

Xu, F., Sadrzadeh, A., Xu, Z., and Yakobson, B. I. (2013a). Can carbon nanotube fibers achieve the ultimate conductivity? - Coupled-mode analysis for electron transport through the carbon nanotube contact. J. Appl. Phys. 114:063714. doi: $10.1063 / 1.4818308$

Xu, Z., Liu, Z., Sun, H., and Gao, C. (2013b). Highly electrically conductive agdoped graphene fibers as stretchable conductors. Adv. Mater. 25, 3249-3253. doi: 10.1002/adma.201300774

Xu, T., Zhang, Z. P., and Qu, L. T. (2019). Graphene-based fibers: recent advances in preparation and application. Adv. Mater. 32:1901979. doi: 10.1002/adma. 201901979

Xu, Z., and Gao, C. (2015). Graphene fiber: a new trend in carbon fibers. Mater. Today 18, 480-492. doi: 10.1016/j.mattod.2015.06.009

Xu, Z., Liu, Y., Zhao, X., Peng, L., Sun, H., Xu, Y., et al. (2016). Ultrastiff and strong graphene fibers via full-scale synergetic defect engineering. Adv. Mater. 28, 6449-6456. doi: 10.1002/adma.201506426

Xu, Z., Zhang, Y., Li, P., and Gao, C. (2012). Strong, conductive, lightweight, neat graphene aerogel fibers with aligned pores. ACS Nano 6, 7103-7113. doi: $10.1021 / \mathrm{nn} 3021772$

Yadav, M. D., Dasgupta, K., Patwardhan, A. W., and Joshi, J. B. (2017). High performance fibers from carbon nanotubes: synthesis, characterization, and applications in composites - a review. Ind. Eng. Chem. Res. 56, 12407-12437. doi: 10.1021 /acs.iecr.7b02269

Yan, J., Uddin, M. J., Dickens, T. J., Daramola, D. E., and Okoli, O. I. (2014). 3D wire-shaped dye-sensitized solar cells in solid state using carbon nanotube yarns with hybrid photovoltaic structure. Adv. Mater. Interf. 1:1400075. doi: 10.1002/admi.201400075

Yang, Z., Jia, Y., Niu, Y., Zhang, Y., Zhang, C., Li, P., et al. (2020). One-step wet-spinning assembly of twisting-structured graphene/carbon nanotube fiber supercapacitor. J. En. Chem. doi: 10.1016/j.jechem.2020.02.023

Yin, F., Hu, J., Hong, Z., Wang, H., Liu, G., Shen, J., et al. (2020). A review on strategies for the fabrication of graphene fibres with graphene oxide. RSC Adv. 10, 5722-5733. doi: 10.1039/C9RA10823H

Yu, D., Goh, K., Wang, H., Wei, L., Jiang, W., Zhang, Q., et al. (2014). Scalable synthesis of hierarchically structured carbon nanotube-graphene fibres for capacitive energy storage. Nat. Nanotechnol. 9, 555-562. doi: 10.1038/nnano. 2014.93

Yun, Y. J., Ah, C. S., Hong, W. G., Kim, H. J., Shin, J.-H., and Jun, Y. (2017). Highly conductive and environmentally stable gold/graphene yarns for flexible and wearable electronics. Nanoscale 9, 11439-11445. doi: 10.1039/C7NR04384H

Zeng, J., Ji, X., Ma, Y., Zhang, Z., Wang, S., Ren, Z., et al. (2018). 3D graphene fibers grown by thermal chemical vapor deposition. Adv. Mater. 30:1705380. doi: 10.1002/adma.201705380

Zhang, J., and Fahrenthold, E. P. (2019). Potassium-doped graphene nanoribbons for high-specific conductivity wiring. ACS Appl. Nano Mater. 2, 2873-2880. doi: 10.1021 /acsanm.9b00327

Zhang, L., Wang, J., Fuentes, C. A., Zhang, D., Van Vuure, A. W., Seo, W. J., et al. (2017a). Wettability of carbon nanotube fibers. Carbon 122, 128-140. doi: 10.1016/j.carbon.2017.06.027

Zhang, S., Park, G. J., Nguyen, N., Jolowsky, C., Hao, A., and Liang, R. (2017b). Ultra-high conductivity and metallic conduction mechanism of scaleup continuous carbon nanotube sheets by mechanical stretching and stable chemical doping. Carbon 125, 649-658. doi: 10.1016/j.carbon.2017.09.089

Zhang, M., Atkinson, K. R., and Baughman, R. H. (2004). Multifunctional carbon nanotube yarns by downsizing an ancient technology. Science 306, 1358-1361. doi: $10.1126 /$ science. 1104276

Zhang, M., Fang, S., Zakhidov, A. A., Lee, S. B., Aliev, A. E., Williams, C. D., et al. (2005). Strong, transparent, multifunctional, carbon nanotube sheets. Science 309, 1215-1219. doi: 10.1126/science.1115311 
Zhang, S., Nguyen, N., Leonhardt, B., Jolowsky, C., Hao, A., Park, J. G., et al. (2019). Carbon-nanotube-based electrical conductors: fabrication, optimization, and applications. Adv. Ener. Mater. 5:1800811. doi: 10.1002/aelm.20180 0811

Zhang, X., Li, Q., Holesinger, T. G., Arendt, P. N., Huang, J., Kirven, P. D., et al. (2007). Ultrastrong, stiff, and lightweight carbon-nanotube fibers. Adv. Mater. 19, 4198-4201. doi: 10.1002/adma.200700776

Zhao, Y., Wei, J., Vajtai, R., Ajayan, P. M., and Barrera, E. V. (2011). Iodine doped carbon nanotube cables exceeding specific electrical conductivity of metals. Sci. Rep. 1:83. doi: 10.1038/srep00083

Zheng, B., Gao, W., Liu, Y., Wang, R., Li, Z., Xu, Z., et al. (2020). Twist-spinning assembly of robust ultralight graphene fibers with hierarchical structure and multi-functions. Carbon 158, 157-162. doi: 10.1016/j.carbon.2019.11.072

Zhong, X. H., Li, Y. L., Liu, Y. K., Qiao, X. H., Feng, Y., Liang, J., et al. (2010). Continuous multilayered carbon nanotube yarns. Adv. Mater. 22, 692-696. doi: 10.1002/adma.200902943
Zhou, E., Xi, J., Liu, Y., Xu, Z., Guo, Y., Peng, L., et al. (2017). Large-area potassiumdoped highly conductive graphene films for electromagnetic interference shielding. Nanoscale 9, 18613-18618. doi: 10.1039/c7nr07030f

Conflict of Interest: The authors declare that the research was conducted in the absence of any commercial or financial relationships that could be construed as a potential conflict of interest.

Copyright (c) 2020 Cesano, Uddin, Lozano, Zanetti and Scarano. This is an open-access article distributed under the terms of the Creative Commons Attribution License (CC BY). The use, distribution or reproduction in other forums is permitted, provided the original author(s) and the copyright owner(s) are credited and that the original publication in this journal is cited, in accordance with accepted academic practice. No use, distribution or reproduction is permitted which does not comply with these terms. 


\section{GLOSSARY}

AC, alternating current; AFM, atomic force microscopy; CFs, carbon fibers; CNFs, carbon nanofibers; CNT fibers, carbon nanotube fibers; CNTs, carbon nanotubes; $\mathrm{C}_{\mathrm{sp}}$, specific capacitance; CVD, chemical vapor deposition; DC, direct current; DSSC, dye sensitized solar cell; DWCNTs, double-walled carbon nanotubes; EMI, electromagnetic interference (shielding); FET, field-effect transistor; FIB, focused ion beam, GFs, graphene fibers; GICs, graphite intercalation compounds; GO, graphene oxide; GR, graphene; ID, D-band Raman intensity of graphitic materials; $\mathrm{I}_{\mathrm{G}}$, G-band Raman intensity of graphitic materials; LED, light-emitting diode; MWCNTs, multi-walled carbon nanotubes; PAN, Polyacrylonitrile; PECVD, plasma-enhanced chemical vapor deposition; RBM, radial breathing mode; rGO, reduced graphene oxide; RTM, radial tangential mode; SAXS, small-angle X-ray scattering; SEC, specific electrical conductivity; SEM, scanning electron microscopy; STC, specific thermal conductivity; SWCNTs, single-walled carbon nanotubes; TEM, transmission electron microscopy; TGA, termogravimetric analysis; UV-Vis (spectroscopy), UV-visible (spectroscopy) VGCFs, vapor grown carbon fibers; WAXS, wide-angle X-ray scattering; XPS (spectroscopy), X-ray photoelectron (spectroscopy); XRD, X-ray diffraction; XRT, X-ray tomography. 